9

\title{
Incremental Costs and Benefits of Enhancing the IFS Regulatory Regime in Mauritius
}

\section{Background to the analytical part of the cost-benefit study}

After five years of Mauritius' passing new laws, creating new regulatory and investigatory agencies (i.e. the Financial Services Commission [FSC], the Financial Intelligence Unit [FIU] and the Independent Commission against Corruption [ICAC]) and applying a series of complex additional rules and regulations to providers of financial products/services (i.e. banks, insurers, trusts, management companies etc.) it is timely to ask whether the incremental benefits derived from 'enhanced' regulation have been commensurate with its costs.

Representations made at the joint Commonwealth Secretariat-Bank of Mauritius Seminar on IFS Regulation held in Mauritius on 10-11 April 2006 (referred to as 'the seminar' throughout) suggested strongly that the Mauritian financial services industry was egregiously overburdened. The incremental regulatory load imposed on it since 2002 to meet anti-money laundering (AML) and combating the financing of terrorism (CFT) concerns, through more elaborate know your customer (KYC) and due diligence (DD) requirements, was felt to have been excessive.

Mauritian regulators retort that additional regulation, imposed from abroad, has had to be adopted (unquestioningly) for Mauritius to survive as an international financial centre (IFC), avoiding the stigma of being blacklisted and thus being put out of business. They assert that the cost of additional regulation has to be regarded by the international financial services (IFS) industry as an extra cost of doing business, one that has to be absorbed within the industry's extant operating margins or, if that is not possible, passed on to IFS customers.

The outcome of these two viewpoints may be something that neither the IFS industry in Mauritius nor its regulators (or government) would wish to see. That is, a relentless increase in regulatory costs resulting in no tangible benefits, but undermining the IFS industry's global competitiveness. That would result (as is already happening) in the loss of extant and potential IFS business to other jurisdictions, both established (e.g. London and Singapore) and emerging (e.g. Dubai) ones. 
Hence the need for a more considered review of costs versus benefits, along with a necessary reflective pause for contemplating (dispassionately/impartially) whether the last few years have witnessed a degree of regulatory over-exuberance that needs to be reined back into balance. This study attempts to meet that need, along the same lines as efforts aimed at analysing the costs and benefits of additional AML/CFT regulation that have recently been made in the UK and US. These efforts have yielded disconcerting findings about costs far exceeding any discernible benefits. They suggest the need for more studies and regulatory impact assessments (RIAs) to be undertaken across all jurisdictions, especially in small offshore financial centres (OFCs) like Mauritius.

Mauritius has yet to migrate towards the Basel-2 regime for establishing risk-based capital adequacy requirements for its banking system. Regulatory 'enhancements' between 2002 and 2005 have therefore focused mainly on AML/CFT measures. The exchange of tax information under the OECD's Harmful Tax Practices initiative is being approached in a more gingerly fashion given the sensitivities and multiple legal risks that financial service providing entities in Mauritius feel they would be exposed to by exchanging information under regulatory duress in a way that violates privacy, confidentiality and fiduciary trust when no wrongdoing is alleged or proven.

As observed, the pressure for additional regulation on small OFCs like Mauritius has emanated mainly from external sources (principally the Financial Action Task Force [FATF] via the IMF and World Bank) rather than from within the IFS industry or from national regulators. The reasons for external interlocutors applying such pressure on Mauritian regulators have been many. They range from: (a) avoiding global and regional financial crises by curtailing volatile 'hot money' flows through OFCs; (b) discouraging OFCs from providing a venue for tax avoidance and tax evasion by corporate/individual taxpayers in OECD countries concerned about revenue leakage in the face of rapidly increasing (but questionable and wasteful) public spending; (c) minimising transfer pricing; (d) closing avenues for the laundering of money from large, but well-established illicit global industries, such as trafficking in weapons, narcotics and humans; and (e) preventing terrorism from being financed through the global financial system. These pressures have become particularly pronounced since the events of 11 September 2001 and the 'war on terror' that has been unleashed with much retaliatory emotion, accompanied by the loss of any sense of proportion in applying remedies that are proving to be worse than the disease.

After nearly a decade of argumentation these reasons remain contentious as a basis for the regulatory burdens that are now being globally imposed. Questions are being raised about whether global regulatory authorities and IFIs are not (unwittingly) using traumatic events opportunistically to legitimise intrusions into privacy and confidentiality - two bedrocks of fiduciary trust - that were impermissible before. Most of all there is questioning of whether a 'one size fits all' approach to financial regulation for AML/ CFT, and the setting up of costly Financial Intelligence Units (FIUs) in every country, is appropriate or affordable. There is even suspicion in some circles about whether excessively burdensome financial regulation being imposed by the FATF and IFIs is not 
being used as a non-tariff barrier against OFCs by OECD governments anxious to protect their own IFS industries and eliminate the competition that OFCs are threatening them with.

In trying to achieve over-ambitious global social, economic and political goals through financial regulation, and highlighting the escape valves that OFCs (all of which have axiomatically been tarred with the brush of being ill-regulated, regardless of evidence to the contrary in specific instances) allegedly provide unscrupulous entities and terrorists with, the point often appears to be lost on the FATF, IFIs, OECD governments and their regulators, that the intractable, underlying problems that such regulation is meant to address have been created largely by the unintended consequences of their own policies, as well as by their failures of governance, interdiction and law enforcement. These problems have not been created or encouraged by OFCs; least of all by OFCs that have traditionally been as well regulated as Mauritius. Such issues are illsuited to being tackled tangentially through the creation and application of elaborate, but ultimately ineffectual sieves in OFCs as a palliative. That arabesque only diverts attention from where the real solutions to these problems lie.

In such instances, the imposition of additional regulatory burdens on OFCs, accompanied by the threat of blacklisting if they are not complied with, raises fundamental questions about fairness, perspective and integrity in the conduct of international relations between large and small states with unequal bargaining power. Such questions become more troublesome when there is no recognition on the part of the OECD or IFIs that substantial costs are being imposed on parties who may not (directly or indirectly) benefit from their incurrence. Nor is there any recognition that under such circumstances there may be a powerful moral and legal case (under international law) for compensatory redress when costs and benefits might be so asymmetrically distributed.

Where the problem of money-laundering is concerned, it is simply not credible to believe or assert (as the FATF, IFIs and OECD governments implicitly seem to be doing) that illicit global financial flows from a variety of proscribed activities, estimated by various agencies to total \$3-4 trillion a year, are amenable to being even temporarily or slightly inconvenienced by adding to a mountain of AML legislation and regulation in OFCs. Nor is terrorist financing - more easily handled through pervasive hawala markets, barter and cash transactions financed from the opium, arms and human trafficking industries - likely to be prevented by OFCs adhering to the FATF's obiter dicta on CFT.

Indeed the circumstantial and anecdotal evidence is mounting that more such AML/ CFT regulation in OFCs might actually be counterproductive: creating a monumental, but ultimately useless, paralytic regulatory industry with its own codes, language and vested bureaucratic career and travel interests, while diverting attention from the real problems that such regulation is ostensibly attempting to address. As has been said, the attempt to contain such large volumes of illicit financial flows through AML/CFT regulation is akin to taming Niagara Falls with a tea strainer. 
The approach taken so far by the FATF and the IFIs to the imposition of a plethora of new regulatory measures and standards concerning AML/CFT across all jurisdictions, and most forcefully in OFCs (whose guilt has been assumed before their innocence is proven), appears to be based on the presumption that the overriding benefit of such regulations is so obvious in safeguarding the integrity of the global financial system, that almost any level of cost incurred by anyone anywhere in applying them is acceptable and should not be questioned.

However, the evidence emerging from cost-benefit studies in developed jurisdictions is that: (a) the costs of additional AML/CFT regulation being imposed are much too high and spread across regulators, industry operators and consumers; (b) the benefits to jurisdictions incurring such costs are mainly reputational, albeit judged against arbitrary standards of probity, but such benefits are far too low, elusive, generally unquantifiable and probably accrued in jurisdictions different to those where very quantifiable and visible costs are being incurred without any provision for compensating for that asymmetry; and (c) the burden of surveillance and policing is being shifted decisively - and inappropriately - from regulatory and investigatory agencies to banks and other private financial service providers whose relationships with their customers are being compromised in the process.

Banks and financial institutions are now being obliged by AML/CFT regulation and $\mathrm{KYC} / \mathrm{DD}$ requirements to become policemen, spies, informants and tax collectors visà-vis their customers. These roles involve major conflicts of interest. They leave financial institutions vulnerable to open-ended legal risk on both sides: i.e. on the one hand by customers who believe their basic rights to confidentiality and privacy in transactions involving fiduciary trust are being episodically infringed if not systematically violated and, on the other, by regulators who believe that financial institutions are not being enthusiastic enough in performing their policing and spying jobs for them.

The foregoing arguments are not made in the spirit of denigrating, or opposing for the sake of opposition, what is being done nationally and globally in order to safeguard the probity, integrity, stability and soundness of financial systems. That would be unreasonable. The argument instead is for the restoration of a sense of regulatory balance, perspective and proportion, taking costs and benefits into account, and assessing their impact before designing and applying new AML/CFT and other financial regulations. It is an argument that cautions OFCs like Mauritius against the dangers of interpreting and applying the FATF's standards and IFI recommendations in ways that are so meticulous, unthinking, rigid and draconian, that they threaten the viability and existence of the very system that these regulations are intended to safeguard and protect.

\section{Financial regulation in Mauritius: background for the study}

Contrary to general public opinion in the OECD world about the supposed laxity of regulation in all offshore financial centres (fostered and exaggerated by occasionally questionable observations made by official sources, and by sensationalist journalism about the risks that OFCs pose to global systemic integrity and stability) Mauritius has 
always been a relatively well-regulated OFC. This is a historical reality that the country has been given very little credit for by its external interlocutors. The Mauritian government was emphatic about putting in place sound regulation right at the inception of its OFC. Yet, it has been tarred (unfairly) with the same brush as other OFCs that are not so well regulated.

This part of the study tries to assess the costs incurred and the benefits derived by public and private institutions in the IFS industry from the adoption of AML/CFT regulation in Mauritius since 2002. It responds to a growing sentiment on the part of the IFS industry (and indeed on the part of some thoughtful regulators themselves, as reflected in the balanced views expressed by the incoming CEO of the Financial Services Commission [FSC] at the seminar cited above) that the evolving IFS regulatory regime needs to be re-examined in terms of both its overall cost-benefit ratio as well as its overall 'appropriateness', effectiveness and its impact on competitiveness.

Any regulatory regime has to be questioned that leaves those being regulated as dissatisfied and oppressed as the IFS industry in Mauritius appears to be. It also has to be readjusted to command the respect that is necessary for compliance to be helpful and voluntary rather than begrudging and resentful. For financial regulation to work as it should, those being regulated need to be convinced that it is being done in the best interests of their firms, their customers and the financial system. Internal compliance at the level of the firm, and peer-pressured compliance within the financial services industry, must be incentivised positively. It should dovetail seamlessly with the supervisory efforts of regulators to ensure substantive compliance of a kind that is meaningful, rather than process compliance that results in financial service providers filling out reams of useless forms in a desultory manner that is at cross-purposes with genuine compliance.

As explained earlier, Mauritius has always been eager (perhaps too eager) to comply with international standards established by recognised standard-setting organisations. To avoid the prospect of blacklisting by the FATF, it adopted all its recommendations promptly and applied them with a vigour that was demonstrably absent in many developed financial jurisdictions and most developing ones. The country has demonstrated its willingness to adhere to new principles of international co-operation and information sharing in the case of financial crimes. It was among the first six countries to have made commitments to the OECD after its report on harmful tax competition - modified to the euphemism 'harmful tax practices' after the internal contradiction of the proposition that tax competition among governments could be harmful was pointed out - was issued in $1998^{1}$ (again perhaps an example of misplaced over-eagerness to please) and is now a participating partner at the Global Tax Forum.

Mauritius now has double tax avoidance treaties (DTAT's) with some 30 jurisdictions. It relies on the exchange of information clause in those treaties to provide/obtain tax information in deserving cases to/from foreign tax authorities. It has signed multilateral and bilateral conventions for mutual legal assistance in criminal matters. It was a founding member of the Eastern and Southern African Anti-Money Laundering Group 
(ESAAMLG), a regional organisation styled on the FATF, in which it plays a leading role. The Mauritian FIU is a member of the Egmont Group, fully engaged in the exchange of intelligence with its counterparts in various jurisdictions by pursuing electronic and paper-trails to track the flow of suspicious funds. As a member of IOSCO, Mauritius adheres to the multilateral memorandum of understanding (MOU) on exchange of information on securities and market fraud. Its two main financial supervisors - i.e. the Bank of Mauritius and the Financial Services Commission - have signed numerous MOUs for exchanging information with their counterparts in a number of jurisdictions and have created the necessary legal channels to supply such information in confidence.

The country has regularly and actively participated in the IMF's Information Program, collecting and providing information on financial statistics and the aggregate flow of funds within the context of the General Data Dissemination System (GDDS). The willingness of Mauritius to participate in worldwide AML/CFT efforts and contribute to systemic financial integrity and stability at the international level cannot be doubted; especially as it has, so far, been willing to incur the very high costs involved without demur. However, the burden of incremental financial regulation since 2002 has been such that the question is now being asked - with increasing frequency and intensity by the IFS industry (and, as noted above, by some of the more thoughtful regulators themselves) - about the benefits that have been generated for the country from such collaboration and whether they have been commensurate with the costs.

\section{The coverage of the Mauritius study}

The Mauritius study focused on those local operators that are most active in the IFS business, namely the management companies (but not captive trusts) and banking institutions that are the main providers of IFS to offshore (and some affluent domestic) individual and corporate clients. Management companies (MCs) and banks are particularly vulnerable to international fraud and money laundering abuses perpetrated by clients they do not know well. However, Mauritian entities have a reputation for conservatism that disinclines them to do business with clients they do not know or who are not soundly referred.

Regrettably, the study in Mauritius did not cover insurance companies, securities brokerages, asset management companies, accounting firms or law firms. They were deemed, at the local level, not to be as involved in providing IFS, although many of them are involved in IFS indirectly. Nevertheless, as became apparent at the seminar cited above, representatives of these firms felt strongly that they should have been included in the study. They too have been dramatically affected by the application of AML/CFT regulations. They felt (correctly) that their inclusion in the study would have provided a better and wider picture of the total economic cost to Mauritius of applying externally imposed AML/CFT regulations. As matters stand, the total costs explicated below therefore represent only a significant fraction of the total economic cost that Mauritius has incurred in applying additional AML/CFT regulations at the behest of the FATF and the IFIs. 
Of the 32 (37.6 per cent out of 85 ) management companies that responded to the questionnaire sent out, 82 per cent offered accounting and legal services, 61 per cent offered fund administrative services, while 30 per cent provided other non-bank financial services. All of the companies are required to exercise due diligence and to verify clients' identity under the Financial Intelligence and Anti-Money Laundering Act (FIAMLA). Further they are required to comply with the codes on the prevention of money laundering issued by the BoM (for banks) and the FSC (for trust and management companies, as well as other NBFIs) in line with FATF recommendations. Of the 15 (out of 18) banks that responded to the questionnaires some had, within their overall corporate holding company structures, affiliated captive management companies (some of which did respond to the survey).

Questionnaires were also sent to the Ministry of Finance (which is ultimately responsible for the financial system and IFS industry in Mauritius) the two principal regulatory authorities (BoM and FSC) as well as the Financial Intelligence Unit (FIU). These institutions deal directly with Mauritius' external interlocutors (i.e. the two principal IFIs, OECD counterparts and the FATF) and are the main transmission mechanisms for domestic regulatory shocks triggered/transmitted by external agencies.

The remainder of this chapter comprises three separate sections. The first (section 9.1) examines the costs incurred by public regulatory institutions as well as the private sector (i.e. banks and management companies) in Mauritius in implementing the new AML/CFT regime that has been evolving since 2002. The second (section 9.2) considers the benefits derived from implementation of additional AML/CFT regulation, while the third (section 9.3) attempts an assessment of the net benefits derived from application of the AML/CFT regime in the country. For obvious reasons, such an assessment is rendered difficult by the reality that compliance with AML/CFT regulations is inextricably intertwined with other regulatory compliance requirements that the institutions surveyed must also meet.

In a number of cases, respondents to questionnaires provided qualitative, impressionistic ratings (e.g. high or low) to specific questions asking them to specify in numerical (dollar or rupee) terms the costs and benefits of incremental AML/CFT regulation under particular categories (e.g. staff, training, IT systems, audit costs, legal costs etc.). However, in most cases respondents provided their best retrospective estimates.

\section{Sample size and representativeness}

The response to questionnaires sent out for the study to all management companies and banks was surprisingly large given the delays that occurred locally in sending them out and the limited time that respondents were given to complete and return them. Under the circumstances the response was gratifying. In the absence of those two factors, and with better guidance provided to respondents, the study would have yielded more thorough and accurate quantitative information on costs and benefits. A review of the questionnaire returns suggests that in some cases the questionnaires were referred to junior personnel who probably did not fully understand the business of the 
respondent or were unable to interpret the questions sufficiently accurately to provide responses that were consistent or comprehensible. However, such cases were the exception rather than the rule. In an impressive number of instances, the questionnaires were completed by senior executives of MCs who made many illuminating and informative annotations in their replies.

In that connection, the efforts made by the CEO of the Mauritius Bankers Association (MBA) to garner a maximum response rate from the banking community deserve special mention. She intervened personally on two separate occasions in March and April 2006 to ensure that as many banks as possible responded to the questionnaire. It was regrettable that, despite assurances provided by the MoF about extending full co-operation to the Commonwealth Secretariat and its consultants in undertaking the study, the response from the FIU on its costs was inadequate. The Ministry itself provided useful information before the seminar, as did the FSC and the BoM after the seminar.

Out of 85 management companies (MCs) operating in Mauritius, 32 responded to the questionnaires sent out. This understates the representativeness of the sample in terms of market coverage. When the 32 respondents are split into small ( $0-15$ employees), medium (16-40 employees) and large (over 40 employees) MCs the response pattern was 21 out of 66 small MCs; 4 out of 9 medium-sized MCs; and 7 out of the 10 largest MCs. That distribution makes a significant difference in terms of market coverage. The ten largest MCs in Mauritius account for 60 per cent of the total IFS market, while the nine medium MCs account for a further 15 per cent. The remaining 25 per cent is accounted for by the 66 small MCs, of whom nearly 33 per cent responded. Thus the response by MCs suggests market coverage of about 65 per cent, although only 37.6 per cent of the total number of MCs responded. The 15 out of 18 banks ( 83 per cent) that responded represent over 90 per cent of banking services market coverage for IFS in the country. Under the circumstances, despite some avoidable local hiccups, the response rate has to be considered satisfactory and the study's findings representative.

\section{I The quantifiable incremental costs of new $\mathrm{AML} / \mathrm{CFT}$ regulation in Mauritius}

\section{Introduction}

The study tried to determine quantitatively the incremental costs incurred in Mauritius (by private operators as well as public regulators) attributable to the AML/CFT regime introduced in 2002 (and updated regularly since). Costs were broken down into three main categories:

- Costs related to the formulation of the company's internal policies, rules and procedures on complying with AML/CFT regulations. This category covers the costs of developing and codifying corporate policies and procedures established to manage and mitigate AML/CFT risk in accordance with regulatory requirements. Respondents were asked to provide information on costs related to establishing the corporate regime for dealing with AML/CFT broken down into further sub-catego- 
ries: staff, training, IT hardware and software investments, space, office overheads and other costs.

- Costs related to the actual collection, processing, evaluation and safe storage of required information for KYC and DD purposes. These costs cover: (a) collection and compilation of information about clients and its verification; and (b) the costs of exchanging such information with other institutions. Establishing and using the client information database developed as a result lies at the heart of meeting the requirements of the $\mathrm{AML} / \mathrm{CFT}$ regulatory regime. $\mathrm{KYC} / \mathrm{DD}$ regulations require management companies and banks (as well as other financial service providers) to obtain from clients detailed addresses and identities with proof of same, and to lift corporate veils by going behind the identity of named clients to determine the actual beneficial ownership of the entities being serviced. KYC/DD involves undertaking a thorough search on the background and integrity of clients and making a business decision on their soundness.

- Costs incurred in dealing with regulators and enforcement authorities: e.g. for filing suspicious transactions reports (STRs), submission of information to regulators for 'fit and proper person tests', for license applications, for meeting specific requests made by regulators, co-operating with ongoing investigations and the costs of litigation related to AML/CFT.

The questionnaire sought information on these three categories of total costs incurred by respondents for the four-year period 2002-05 and for the year 2005. It asked respondents to differentiate between costs of a recurrent (annual) nature, and one-off capital expenditures.

\section{Costs incurred by public regulatory and investigative institutions}

As noted earlier, the overall regime for IFS regulation in Mauritius is shaped by the Ministry of Finance $(\mathrm{MoF})$ with the active participation of the Bank of Mauritius (BoM) and the Financial Services Commission (FSC). The latter two institutions also implement IFS regulation/supervision. The BoM regulates banks, while the FSC regulates other financial institutions and service providers. The Financial Intelligence Unit (FIU), an autonomous agency specifically dedicated to AML/CFT intelligence gathering, is not a regulatory body as such. It nonetheless collaborates with the BoM and the FSC. Each of these four public bodies has responsibility within its jurisdictional competence to apply the AML/CFT regime mandated by the MoF.

Ministry of Finance $(\mathrm{MoF})$ : In elaborating regulatory policy and related legislation, and co-ordinating actions at regional and international levels, the MoF has incurred substantial incremental costs (shown in table 9.1, below) so that it might put the AML/ CFT regime in place; however, these costs do not appear to have been a major source of concern.

The single largest cost was that of designing the AML/CFT policy framework based on the FATF's $40+9$ recommendations and drafting legislation to support its implementa- 
Table 9.1 Incremental costs incurred by Ministry of Finance in US dollars (nominal)

\begin{tabular}{lcc}
\hline Cost incurred for & $\begin{array}{c}\text { One-off capital } \\
\text { cost [02-05] }\end{array}$ & $\begin{array}{c}\text { Annual } \\
\text { recurrent costs }\end{array}$ \\
\hline & US\$ & US $\$$ \\
Drafting AML law for NBFIs (+ interest on WB loan) & $1,000,000$ & 60,000 \\
Drafting basic financial intelligence and anti-money laundering law & 50,000 & \\
Drafting AML/CFT amendments \& handbook & 60,000 & \\
Dealing with local costs of IMF-WB FSAP & 30,000 & \\
Meeting local costs of external TA for enforcement & 60,000 & \\
Monitoring \& adjusting AML/CFT regime (1-PY) & & 15,000 \\
Attending regional meetings AML/CFT (ESAAMLG) & & 30,000 \\
Cost of hosting ESAAMLG meeting in 2004 & 30,000 & \\
Annual subscription to ESAAMLG & & 20,000 \\
Other costs (overheads/contingencies etc.) & $1,230,000$ & 140,000 \\
Total Costs & & \\
\hline
\end{tabular}

tion in line with international standards. That involved recruiting international consultants for developing financial legislation in line with the standards of IOSCO, IAIS and IOPS. The work was undertaken as a special project that cost about US\$1 million and was financed by a World Bank loan on commercial terms. It aimed at setting up a non-bank integrated regulatory and supervisory authority (the FSC) and its governance structure as well as reviewing existing laws concerning securities and insurance business.

Further costs were incurred in drafting FIAMLA by a foreign expert, including an estimate of costs for the involvement of the State Law Office. These amounted to US\$50,000. Amendments were made to the law and regulations on the recommendations of the IMF/WB FSAP mission, which required two foreign consultants at a cost of US $\$ 30,000$ each. These consultants also developed an AML/CFT handbook. The development of enforcement procedures made a further call on technical assistance estimated to cost US $\$ 60,000$ (financed in part by the FIRST Initiative). In addition to these one-off 'set-up' costs of US\$1.23 million, spent mainly on the fees of foreign consultants, the Ministry of Finance also incurs annual recurrent costs for:

- Monitoring and adjusting the AML/CFT regime in line with international developments, which costs the MoF the equivalent of a full person-year along with associated overhead and support expenses at an annual cost estimated at US\$15,000 equivalent;

- Attending meetings and conferences overseas by government officials, in particular the ESAAMLG and FATF meetings with each mission estimated to cost US\$15,000 (assuming the participation of the Minister) - consisting of travelling costs, accommodation and per diem payments; 
- Subscriptions to ESAAMLG, which amount to US\$20,000 annually; and

- Interest costs on the World Bank loan that financed the AML/CFT project.

In all, the Ministry incurs an annual recurrent cost of about US\$140,000 for AML/ CFT-related expenditures. For the four years 2002-05, the total recurrent cost has amounted to US\$560,000. Adding the one-off capital costs incurred over the same period, MoF's total incremental costs for AML/CFT between 2002-05 are thus estimated to amount to a total of US\$1.79 million.

\section{Financial Intelligence Unit (FIU) and ICAC}

The FIU was created in August 2002, with its raison d'etre only to gather intelligence on suspicious transactions under AML/CFT regulations. Its entire budget is therefore attributable to incremental AML/CFT costs for the purposes of this study. The Independent Commission Against Corruption (ICAC) was established a year later, but became operational only very recently.

The FIU did not provide any quantitative estimates of its costs for this study. It provided qualitative information indicating that it considered its costs to be low, along with figures on staffing, number of STRs handled etc. It was difficult to discern why the FIU was unable to provide information that was publicly available. Table 9.2 was therefore derived from FIU's 2005 Annual Report, which provided information for only two years (i.e. FY2004 and 2005). No information was available for FY2003. However, given that the FIU only came into existence in August 2002, its expenses in FY2003 would probably not have exceeded 40 to 50 per cent of those registered for FY2004 (that is, about $\$ 200,000$ ). As table 9.2 shows (and estimating start-up expenses incurred in 2003 at $\$ 200,000$ ), the FIU has received capital and recurrent grants from

Table 9.2 Incremental costs incurred by FIU/ICAC in US dollars (nominal)

\begin{tabular}{llrrr}
\hline Cost incurred for & & 2004 & 2005 & $2004-05$ \\
\hline Receipts from government: Capital grant & 253,333 & & \\
& Recurrent grant & 465,137 & 686,460 & $1,151,597$ \\
Expenses from capital grant (for IT systems) & - & 72,097 & 72,097 \\
Annual Expenses: & Salaries \& staff allowances & 254,265 & 380,698 & 634,963 \\
& Training \& seminars & 6,715 & 7,857 & 14,572 \\
& Overseas mission \& conferences & 40,705 & 18,263 & 58,968 \\
& IT-related expenses & 12,094 & 9,229 & 21,322 \\
& Other office \& admin. expenses & 100,397 & 106,458 & 206,855 \\
& Depreciation \& amortisation & 65,537 & 101,057 & 166,594 \\
Total annual expenses & & 479,713 & 623,562 & $1,103,275$ \\
Annual + capital expenses & & 479,713 & 695,659 & $1,175,372$ \\
\hline
\end{tabular}

Source: FIU Annual Report for 2005 posted on its website. Mauritian rupees (MRs) converted to US $\$$ at MRs 30=1 US\$ 
the central government budget amounting to a total of $\$ 1.61$ million, from which it has spent a total of $\$ 1.38$ million up to 30 June 2005 .

In outlining FIU's raison d'etre and activities during the seminar, its representatives seemed overly defensive in overemphasising the supposed social benefits justifying the need for such an agency to prevent money laundering and terrorist financing in Mauritius (although there is little evidence of either) and anxious to deflect attention from its cost. That view was not shared by the IFS industry at large. Nor was it clear that the BoM and the FSC concurred with the need for a financial intelligence gathering function as large, elaborate and expensive as that of the FIU to meet the domestic and international needs of an OFC and domestic financial system the size of Mauritius.

At the time of writing, the FIU had 27 full-time staff to handle an average of about 70 suspicious transaction reports (STRs) a year (for 2004 and 2005) filed by financial institutions with an average of 32 referrals to ICAC for further investigation and possible prosecution. It has decided against referring a further 88 STRs, owing to lack of evidence. In 2005, FIU senior staff undertook or participated in some 19 missions abroad at a recorded cost to the FIU of over US\$18,000. The overall benefit of these to Mauritius is difficult to establish. That number of missions was probably exceeded in 2004, when their total cost was recorded at over US $\$ 40,000$.

Given that the BoM has absorbed the entire incremental cost burden of applying and supervising AML/CFT regime compliance within its existing budget by reallocating staff, the expenditures of the FIU and the extent of its external interactions stand out in contrast.

No cost information was obtained from ICAC. On the basis of personal knowledge, and discussions with staff involved, the local consultant for the study imputed a cost for AML/CFT enforcement by ICAC and the State Law Office (SLO) of about US\$150,000 annually. ICAC accounts for the bulk of that cost as it is principally involved in investigation and seizure actions, with SLO only following up in the case of criminal prosecutions actually being made. In the absence of better information from ICAC, the SLO or any other source, that estimate has been included in the total costs to government of establishing, implementing and maintaining AML/CFT regulation up to June 30, 2005.

\section{Financial Services Commission (FSC)}

The FSC was established in late 2001 with a capital grant from the Government of Mauritius of MRs100 million (US $\$ 3.33$ million), of which MRs24 million (or about $\$ 800,000$ ) was utilised in 2001-02 to set up its initial institutional infrastructure. The FSC licenses and regulates non-bank financial intermediaries (NBFIs) in Mauritius. These include: insurance companies and brokerages, actuaries, management companies, corporate trustees, pension funds and contractual savings schemes, capital market operators (i.e. stockbrokers, investment funds, mutual funds, portfolio managers, investment advisers/agents and market infrastructure providers), leasing and factoring companies, credit and finance companies. 
Table 9.3 FSC total expenditures for 2002-2005 in US\$ million (nominal)

\begin{tabular}{lccccc}
\hline Costs incurred for & 2002 & 2003 & 2004 & 2005 & $2002-05$ \\
\hline Staff salaries \& allowances & 0.962 & 1.134 & 1.522 & 2.138 & 5.756 \\
Staff training \& overseas seminars (20:80) & 0.074 & 0.102 & 0.267 & 0.250 & 0.693 \\
Legal \& professional fees & 0.056 & 0.114 & 0.034 & 0.178 & 0.382 \\
General office \& admin. expenses & 0.418 & 0.730 & 0.831 & 1.035 & 3.014 \\
Depreciation \& amortisation & 0.064 & 0.223 & 0.406 & 0.248 & 0.941 \\
Non-recurrent set-up costs & 0.800 & 0.003 & - & - & 0.803 \\
Total expenditures & 2.374 & 2.306 & 3.060 & 3.849 & 11.589 \\
Memo: Capital grant from government & 3.333 & - & - & - & - \\
From which expended for set-up costs & 0.800 & 0.003 & - & - & - \\
Balance of capital grant available & 2.533 & 2.530 & 2.530 & 2.530 & 2.530 \\
Memo: Revenues from license fees & 3.090 & 7.890 & 6.127 & 7.403 & 24.510 \\
Interest income from cash surplus & 0.196 & 0.381 & 0.506 & 0.897 & 1.980 \\
Memo: Capital expenses on IT & 0.139 & 0.016 & 0.085 & 0.463 & 0.703 \\
Total no. of staff & 55 & 82 & 96 & $112(\mathrm{E})$ & \\
Targeted staffing in CEO's Report 2003 & & & $(126)$ & & \\
\hline
\end{tabular}

As of 30 June 2005, the FSC had approved some 29,751 licensees. Of these, 25,900 were global business companies (GBCs), which constitute the core clientele that utilise the services of the IFS industry in Mauritius. Services are provided to GBCs by 85 management companies (and 24 captive corporate trustees, which account for an insignificant fraction of total IFS business) and some 14 (out of 18) banks. The remaining 3,851 licensees were domestic entities of various types. The total costs and expenditures of the FSC (translated into US\$) since its inception are shown in Table 9.3, above, which has been derived from annual reports for 2003 to $2005^{2}$. The FSC is a selffinancing authority that generates a surplus from revenues (principally from license fees) over expenses and accrues the surplus to its own general fund. However, while its revenues might be seen as a benefit to government (and to public finances), they represent a cost (of being allowed to do business) to the financial services industry.

Since its set-up in 2001, the FSC has incurred a total cost of about US\$11.6 million (up to 30 June 2005). Nonetheless, not all of this cost in 2002-05 can be considered additional and attributable to post-2002 regulatory demands for AML/CFT. This is because the FSC assumed the functions (and costs) of the former Mauritius Offshore Business Activities Authority (MOBAA), Securities and Exchange Commission (SEC) and the Controller of Insurance division of the Ministry of Finance.

Given the depth and width of its regulatory/supervisory ambit, the FSC's costs do not appear to be out of line with experience elsewhere. However, the rapid increase in the FSC's costs and staff since 2002 may require further attention. They do not provide a cause for budgetary concern, because the FSC is self-financing and generates a healthy 
surplus. Still, FSC's staffing has more than doubled over the last four years, while its annual (recurrent) expenditures have increased by nearly 150 per cent from US\$1.57 million in 2002 to $\$ 3.85$ million in 2005 . Over that same period the population and diversity of its licensees has grown by under 10 per cent annually (in aggregate by 34 per cent) from a total of 22,276 in 2002 to 29,751 in 2005. Employment in its regulated domain of NBFIs has increased from 2,663 in 2002 to 3,030 in 2005 (or by 13.5 per cent - i.e. less than 4 per cent annually) while the FSC's staff has increased by over 100 per cent over the same period (these figures being derived from table 4 in the FSC's Annual Report of 2005). Those disproportionate increases in the FSC over industry staffing suggest that a considerable amount of incremental effort has been required of the FSC since 2002 in coping with new regulatory demands; such demands are mainly attributable to the new AML/CFT regime, rather than any other identifiable factor.

This observation is made to put the figures in table 9.4, below, in context. The table provides the FSC's own estimates of incremental costs related to the regulatory and supervisory burdens imposed upon it by the adoption and application of new AML/ CFT legislation, which it participated in drafting. Table 9.4 suggests that less than 7.5 per cent of the FSC's total expenditures between 2002 and 2005 were attributable to cost burdens imposed by new AML/CFT demands. However, this (surprisingly low) percentage is open to further scrutiny. About 14 per cent of the FSC's total staffing costs, less than 5 per cent of the FSC's total costs for overseas missions, less than 3 per cent of the FSC's total training costs and less than 1.25 per cent of all other FSC costs

Table 9.4 The Financial Services Commission's estimates of incremental costs for AML/CFT in US\$

$$
\text { Costs incurred for }
$$

FSC costs for 2002-05

Total AML/CFT \%B/A

(A)

(B)

Staffing costs for

1. Drafting AML/CFT legislation (one-off)

2. Assessment $\&$ surveys

3. Participating in AML/CFT National Committee

4. Attending FATF \& ESAAMLG meetings

5. Monitoring/supervising AML/CFT regime

Total staffing costs

Other costs:

Costs of technical assistance to FSC for setting up regime

Provision for creation/operation of specialised agencies

Training costs (for staff \& NBFI industry)

Costs of disseminating information on AML/CFT

Total other costs

Total staffing + other costs
37,000

\begin{tabular}{rrr} 
& 37,000 & \\
& 4,000 & \\
& 30,000 & \\
& 26,700 & $4.8 \%$ \\
554,400 & 683,900 & \\
& 781,600 & $13.6 \%$ \\
$5,756,000$ & & \\
& & \\
& 51,700 & \\
& 2,100 & \\
693,000 & 20,000 & $2.9 \%$ \\
& 4,850 & \\
$5,833,000$ & 78,650 & $1.35 \%$ \\
$11,589,000$ & 860,250 & $7.42 \%$ \\
\hline
\end{tabular}


(i.e. office overheads, equipment etc.) were attributed by the FSC to AML/CFT between 2002 and 2005. Those proportions seem extraordinarily low, if not incredible, given that AML/CFT and related KYC/DD preoccupations have been at the forefront of regulation during those four years. They require further scrutiny in view of the staff/ cost increase that the FSC has incurred. Closer analysis suggests that an estimate of $\mathbf{1 5}$ per cent of the total supervisory costs incurred by the FSC between 2002 and 2005 (or about $\$ 1.74$ million) being attributed to AML/CFT burdens might be closer to the mark than the FSC's estimate of 7.5 per cent ${ }^{3}$. However, as the FSC has undertaken specific analysis for the purposes of this study, the figures provided (rather than an adjusted estimate) are taken into account for the present analysis.

\section{The Bank of Mauritius (BoM)}

The BoM, which regulates and supervises all banks in Mauritius, has provided the following figures as its internal estimates for the incremental costs of coping with the enhanced AML/CFT regime (see table 9.5, below).

Excluding interest expenses and other charges on its monetary operations, IMF charges and coin and note issuance charges, the BoM's annual staff and other office expenditures in 2002-05 amounted to an aggregate US\$38.5 million or an annual average of US\$9.6 million. That is low for a central bank of this size and reflects tight control over management and administrative costs. Probably, around 25 per cent of the BoM's total administrative cost is attributable to regulation and supervision, given the number of other activities that the BoM has to undertake. Roughly, that would imply a total of US\$9.6 million being spent on supervisory functions over the four-year period in question. However, the BoM has provided information for only three of those four years. Adjusting for that, the incremental cost incurred by the BoM for coping with

Table 9.5 The Bank of Mauritius's incremental costs for AML/CFT in US\$ (nominal)

Costs incurred between 2002 and 2005 for

Total costs

2002-05

\section{Non-recurrent}

1. Preparation of internal AML/CFT guide for bank examiners

2. Preparation of AML/CFT guidance notes for all BoM regulated institutions

3. Costs of training provided by external consultants to BoM staff

Total non-recurrent costs

Recurrent

4. Staff and training costs attributed to AML/CFT: 2002-03 38,615

(BoM believes $15 \%$ of its S/T costs 2003-04

59,930

are attributable to AML/CFT) 2004-05

62,667

Total non-recurrent costs:

161,212

Total recurrent + non-recurrent costs

184,760 
incremental AML/CFT burdens amounts to 2.6 per cent of its imputed total costs for regulation and supervision.

Looking at the negligible increase in staffing, it appears that the BoM has coped with additional AML/CFT burdens by reallocating work among its extant staff base and has stretched its staff through overtime. That impression was confirmed in private discussions with the BoM senior management during the course of the seminar. Nonetheless, stretching staff resources can only be done up to a point. It is not an indefinitely sustainable proposition. Sooner or later the BoM will need to increase staff to cope with the additional regulatory burdens being placed upon it. That will mean that the incremental costs of AML/CFT burdens will not be fully reflected in the BoM's accounts until 2006 or beyond.

\section{Total (incremental) public sector costs for AML/CFT}

Putting these costs for all public institutions involved with AML/CFT together results in the following picture (see table 9.6).

For the four years 2002-05, the Mauritian government and public agencies have spent nearly $\$ 5$ million in incremental costs for developing and administering its AML/ CFT regulatory regime in accordance with recommendations made by the FATF and IFIs for bolstering that regime. A third of these expenditures have been one-off capital costs. The total cost, while high in the context of Mauritius, pales in comparison to the costs incurred by private sector operators in the IFS industry.

\section{Management companies and offshore banks: summary profiles}

Private sector institutions were more forthcoming than their public counterparts in providing quantitative estimates of their incremental costs for setting up their own internal AML/CFT compliance machinery and observing AML/CFT regulations. Before the seminar, some 32 management companies (MCs) had returned completed (or partially completed) questionnaires, while nine banks had done so. After the seminar, further follow up by the CEO of the MBA resulted in six more banks providing the required information.

Table 9.6 Total AML/CFT costs for public institutions in US\$

\begin{tabular}{|c|c|c|c|}
\hline \multirow[t]{2}{*}{ Institution } & \multicolumn{3}{|c|}{ Incremental AML/CFT costs for 2002-05 period } \\
\hline & Non-recurrent & Recurrent & Total \\
\hline Ministry of Finance $(\mathrm{MoF})$ & $1,230,000$ & 560,000 & $1,790,000$ \\
\hline Financial Intelligence Unit (FIU) & 272,100 & $1,103,300$ & $1,375,400$ \\
\hline ICAC \& State Law Office (SLO) & n.a. & 600,000 & 600,000 \\
\hline Financial Services Commission & 90,800 & 769,500 & 860,300 \\
\hline Bank of Mauritius (BoM) & 23,500 & 161,200 & 184,760 \\
\hline Total Public Sector Costs: & $1,616,400$ & $3,194,000$ & $4,810,460$ \\
\hline
\end{tabular}


Before going directly into an analysis of questionnaire returns, it is essential to establish a profile of the two main types of players engaged in providing IFS to offshore clientele (which mainly comprise the two types of global business companies - GBC-1 and GBC-2 licensees). These two main players are: (a) management companies and (b) banks. Summary profiles of both groups are provided in tabular form below.

As table 9.7 indicates, at the end of June 2005 there were 85 management companies operating in Mauritius (although more licenses were issued, indicating that some were dormant, defunct or in the process of being wound up) compared to about 70 operating in 2001. Together they employed just over 1,000 people and had a wage bill approaching US\$12 million (compared to $\$ 5.4$ million in 2001). From the different percentages of MCs responding to the FSC's annual surveys it is not easy to extrapolate figures for the MC industry as a whole without knowing the size distribution of the responses received. The larger companies generally showed a much higher response rate than the smaller companies. Nevertheless, wherever possible the table shows extrapolated figures for the industry based on best assumptions and estimates.

Similarly, Table 9.8, below, provides a summary profile of banks in Mauritius.

Table 9.7 Summary profile of management companies in Mauritius

\begin{tabular}{|c|c|c|c|c|c|}
\hline Characteristics & 2001 & 2002 & 2003 & 2004 & $2005[E]$ \\
\hline Number of MCs operating & 70 & 71 & 79 & 81 & 85 \\
\hline Number of MCs reporting in FSC survey & 38 & 57 & 69 & 67 & n.a. \\
\hline Number of employees for reporting MCs & n.a. & 457 & n.a. & 813 & n.a. \\
\hline Approx. total extrapolated for all MCs & 510 & 600 & 785 & 950 & 1,015 \\
\hline Employee compensation (US\$ million) & 3.62 & 5.16 & 6.69 & 9.07 & na \\
\hline Extrapolated for all MCs (US\$ million) & 5.40 & 6.85 & 9.14 & 11.78 & 12.45 \\
\hline Other expenses (US\$ million) & 11.73 & 13.12 & 10.97 & 9.73 & na \\
\hline Purchases of goods $\&$ services (US\$ million) & 2.03 & 5.73 & 9.18 & 10.81 & na \\
\hline Total expenses incl. tax (US\$ million) & 16.38 & 24.01 & 26.84 & 39.61 & na \\
\hline Gross income (US\$ million) & 23.69 & 29.40 & 33.06 & 41.16 & na \\
\hline \multirow[t]{2}{*}{$\mathrm{o} / \mathrm{w}$ accounted for by largest 10 (US $\$$ million) } & 19.92 & 21.80 & 13.20 & 21.80 & na \\
\hline & $67 \%$ & $63 \%$ & $54 \%$ & $59 \%$ & na \\
\hline Growth rate of turnover & $+24 \%$ & $+16 \%$ & $-28 \%$ & $+54 \%$ & na \\
\hline Profits before tax (US\$ million) & 10.48 & 9.84 & 6.19 & 10.79 & na \\
\hline \multirow{2}{*}{$\begin{array}{r}\mathrm{o} / \mathrm{w} \text { accounted for by largest } 10 \text { (US\$ million) } \\
\text { : as percentage }\end{array}$} & 9.80 & 9.50 & 5.30 & 9.20 & na \\
\hline & $87 \%$ & $82 \%$ & $77 \%$ & $76 \%$ & na \\
\hline Profits after tax (US\$ million) & 7.31 & 5.38 & 6.22 & 1.56 & na \\
\hline Gross assets (US\$ million) & n.a. & 38.16 & 36.99 & 43.09 & na \\
\hline
\end{tabular}

Source: FSC annual reports for 2003, 2004, 2005. 
Table 9.8 Summary profile of offshore banks in Mauritius

\begin{tabular}{lccccc}
\hline Characteristics & 2001 & 2002 & 2003 & 2004 & 2005[E] \\
\hline Number of banks & n.a. & 12 & 11 & 18 & 18 \\
Number of banks operating domestically (C-I) & n.a. & 10 & 10 & 11 & 11 \\
Number of banks providing IFS (C-II) & n.a. & 9 & 12 & 12 & 12 \\
Gr. value added by offshore banks (US\$ mill.) & 68.3 & 70.1 & 80.4 & 82.4 & 85 \\
No. of employees for offshore banks & n.a & 512 & 562 & 588 & 643 \\
No. of employees in the banking sector & n.a. & 4,353 & 4,586 & 4,697 & 5,371 \\
Employee compensation (US\$ million) & 3.1 & 3.7 & 3.8 & 5.2 & n.a. \\
Other expenses & 5.8 & 6.3 & 6.5 & 9.8 & n.a. \\
Operating income & 114.0 & 110.8 & 77.7 & 86.7 & n.a. \\
Total operating expenses & 8.9 & 10.0 & 10.5 & 15.0 & n.a. \\
Net profit before tax (US\$ million) & 105.1 & 100.8 & 67.2 & 71.7 & n.a. \\
Gross assets (US\$ million) & 3,940 & 4,320 & 4,689 & 6,617 & 7,886 \\
\hline
\end{tabular}

Source: BoM annual reports for 2003 and 2004 and FSC annual report for 2005 (for employment figures).

The banking sector in Mauritius is divided into the domestic commercial banking sector and the offshore banking sector. Eleven Category 1 (C-1) banks operate in the domestic banking sector. Of these, five are local banks, two are wholly owned subsidiaries of foreign banks that are incorporated locally and four are branches of foreign banks. Twelve banks hold a Category 2 (C-2) license to operate in the offshore banking sector. Of these, seven banks provide only IFS. The remaining five undertake both domestic banking and IFS, but with a dividing wall between these two types of operations.

These two sets of profiles need to be kept in mind in interpreting the responses provided by MCs and banks on their incremental AML/CFT cost burdens and the qualitative responses provided to amplify on the quantitative information provided.

\section{Management companies: analysis of questionnaire responses on costs}

Taking into account the three main cost categories that respondents were asked to provide quantitative data for (i.e. costs for developing their internal AML/CFT compliance regime; costs of creating their KYC/DD data bases; and costs of preparing, submitting and responding to queries about STRs) the summary picture for the 30 out of 32 responding management companies that provided quantitative data is portrayed below (table 9.9). Aggregate figures for all 85 management companies are extrapolated using simple averages derived from the returns for each type of MC. Although this approach may not yield the most accurate results for the total costs of the MCs, it nevertheless provides a useful illustrative/indicative figure. 
Table 9.9 Incremental AML/CFT costs for management companies 2002-2005 (US\$)

\begin{tabular}{lrrrr}
\hline Costs incurred by MCs in Mauritius for & Small & Medium & Large & Total \\
& $(20)$ & $(4)$ & (6) & (30) \\
\hline
\end{tabular}

From sample responses received

1. Establishing internal compliance regime

$\begin{array}{rrrr}1,808,400 & 311,400 & 3,973,300 & 6,093,100 \\ 1,344,580 & 334,000 & 3,462,400 & 5,140,980 \\ & & & \\ 419,700 & 42,300 & 528,500 & 990,500 \\ 3,572,680 & 687,700 & 7,964,200 & 12,224,580\end{array}$

2002-2005

Memo: Average costs per type of MC

1. Establishing internal compliance regime

\begin{tabular}{rrrr}
90,420 & 77,850 & 662,220 & 203,100 \\
67,230 & 83,500 & 577,100 & 171,366 \\
& & & \\
27,980 & 14,100 & 105,700 & 33,016 \\
185,630 & 175,450 & $1,345,020$ & 407,486 \\
{$[66]$} & {$[9]$} & {$[10]$} & {$[85]$} \\
$5,967,720$ & 700,650 & $6,622,200$ & $13,290,570$ \\
$4,437,180$ & 751,500 & $5,771,000$ & $10,959,680$ \\
& & & \\
$1,846,680$ & 126,900 & $1,057,000$ & $3,030,580$ \\
& & & \\
$12,251,580$ & $1,579,050$ & $13,450,200$ & $27,280,830$ \\
\hline
\end{tabular}

2. Developing KYC/DD databases

3. Reporting STRs \& regulatory interaction

Incremental AML/CFT costs per MC

Extrapolated totals for ALL MCs

1. Establishing internal compliance regime

[Some of these averages appear different when dividing figures shown by number of MCs because not all companies in each category have reported for all three main categories and sub-categories of cost]

As Table 9.9 shows, the aggregate incremental AML/CFT regulatory cost for all MCs for the four-year period 2002-2005 is extrapolated (from sample return averages) to amount to nearly $\$ 27.3$ million. A close scrutiny of individual returns suggests that this figure may be understated for a variety of reasons. First, many respondents registered larger amounts for costs for the single year 2005 (for which they had recent data readily to hand) than they did for the four-year period 2002-2005, suggesting that they either read the period as 2002-2004 or did not focus on reconciling their responses. Second, many respondents have provided overall estimated figures for each of the three main cost categories without providing breakdowns for the several sub-categories of costs included (e.g. staffing, training, IT costs, audit costs overheads etc.) There is a consistent pattern of understatement when aggregate figures, without breakdowns, are related 
to totals supported by detailed breakdowns. Third, some costs appear obviously understated when total costs for many MCs are lower than just audit costs reported by other similar sized companies. For these and other reasons, a reasonable guess based on detailed scrutiny suggests a degree of understatement in the range of 30-40 per cent. However, no adjustment has been made for such understatement in the analysis that follows.

The pattern of response across different types of MCs (by size) also suggests some interesting contradictions, characteristics and other anomalies that need to be investigated further (in another study) to determine the accuracy of the returns. This was not possible to do under the time and budget constraints that this study operated under.

For example, total average incremental costs for small MCs were larger than for medium-sized MCs. Average dollar costs for AML/CFT compliance regime development were higher for small MCs than for medium-sized MCs, while average costs for establishing KYC/DD databases were significantly lower. The average costs of STRs and regulatory interaction reported by small MCs were double those of medium-sized companies. That is difficult to explain unless it is presumed that smaller MCs may have riskier clients who generate a higher proportion of suspicious transactions. This type of superficial anomaly needs further exploration and clarification.

The ten largest MCs dominate in accounting for 65 per cent of the industry's total AML/CFT costs. That is unsurprising given their 60 per cent share of the total MC market, and their even larger share of gross and net incomes derived from the provision of IFS. Average incremental AML/CFT costs for large MCs was 8-10 times higher than for small and medium MCs.

Interestingly, in the group of MCs classified as 'small', there were in-house affiliates of global groups like ING, Investec and Halifax. An affiliate of Fidelity Trust was classified as 'medium-sized'. On the face of it, these names would suggest classification in the 'large' category, given the likely size of their in-house business. Although small in terms of number of employees, these affiliates may be large in terms of business volume, although the questionnaires circulated (which were modified locally without further reference to the lead consultants) did not explicitly ask that question.

Another pointer to the probable understatement of overall costs was the wide range of variation in the responses of MCs of different sizes. For example, small MCs reported variations in total AML/CFT incremental costs from a low of US $\$ 25,000$ to a high of US\$750,000, with statistical medians being quite different to (and more meaningful than) arithmetic averages. The range of variation for more detailed sub-breakdowns (e.g. staffing costs) was even wider. The variation for medium-sized MCs was much lower, however, ranging from a low of US\$86,000 to a high of US\$319,000. The variation for large MCs was higher than for medium MCs, but much lower than for smaller MCs, with a low of US\$387,000 and a high of US\$2.25 million.

Incremental costs for establishing the set-up of their internal corporate AML/CFT compliance machinery and for establishing their KYC/DD databases accounted for 
the largest proportion of total costs for all three types of MC. This was not surprising given the pressure that MCs were under to substantially refurbish their KYC/DD databases on their $25,750 \mathrm{GBC}$ clients retroactively over the four years to 2006 . The largest sub-item of cost for establishing compliance machinery was staffing costs (40 per cent), while the costs of legal and technical assistance for establishing the AML/CFT framework, training costs and IT hardware and software costs accounted for around 16 per cent each, with audit and other costs accounting for the remaining 12 per cent. Incremental expenditures on IT systems for AML/CFT compliance appeared to be low when compared to expenditure patterns for the same purpose in other jurisdictions. The largest cost where the KYC/DD databases were concerned was that of information collection (45 per cent), with the second largest cost being that of verification (26 per cent). Exchanging client information with other parties accounted for 18 per cent of total KYC/DD costs, with safekeeping and other costs amounting to 11 per cent. By comparison, costs for dealing with STRs and interacting with regulatory and investigation agencies were relatively low, accounting for 8.1 per cent for all MCs together (but ranging from 12 per cent for small MCs to 6 per cent for medium MCs and 6.6 per cent for large MCs) and 10.3 per cent for banks.

The low proportion of costs absorbed by STRs and regulatory interaction bears further scrutiny. This finding from questionnaire returns calls into question claims made by the FIU about the urgent and pressing needs for its services. The FIU reported just 65 STRs being filed by financial institutions and MCs in 2004 and 75 in 2005. The filing of STRs with the FIU, investigation by the FIU and ICAC or other law enforcement agencies, and the disclosure of beneficial owners' information to regulators on submission of licence applications creates the most difficulty for MCs with their clients. It puts them in legally untenable conflict-of-interest positions in providing information to regulators, which their clients deem to be a breach of fiduciary trust.

From participant reactions at the seminar, it became clear that banks spend a considerable amount of time and money examining dubious client files. They have recourse to greater internal control and wider checking mechanisms through head-office access, which provides them with global reach in tracking down credit records and other relevant information. However, MCs appear to spend more on: providing information on 'ultimate beneficiary' ownership to the regulator in cases of licence applications; satisfying the criteria established for meeting the 'fit and proper person' test; and responding to requests by the regulator and the FIU for further information. This may be explained by regulatory obligations in the IFS industry requiring disclosure of 'ultimate beneficiary' information to the FSC in respect of GBC-1 licences to strip out corporate veils. MCs have complained loudly that the FSC is much too rigid and bureaucratic in its scrutiny on beneficial owners' information, with demands for supporting information (such as 10-year-old utility bills) that do little to establish the bona fides or purity of motives of GBC license applicants.

Overall, incremental AML/CFT costs for MCs were higher (in absolute and relative terms) than for banks (as shown below). The reason probably is that banks have been subject to creeping increases in regulation since 1998. Banks have therefore been able 
to absorb the incremental burdens of post-2001 AML/CFT legislation/regulation more readily within their overall (already very large) compliance budgets than have management companies, for whom post-2001 AML/CFT regulatory impositions have been particularly demanding and traumatic to adjust to. A second reason (that came out during the seminar) is that the six foreign bank branches/subsidiaries that dominate a significant share of the offshore banking market in Mauritius have most, if not all, of their compliance costs absorbed by head office compliance departments and therefore do not feel the impact of incremental costs on their own budgets or books. This led to a considerable understatement of incremental AML/CFT costs by banks.

Comparing incremental AML/CFT costs to the profitability of MCs and banks highlights another facet (in Table 9.10 below) that explains why MCs have felt more burdened than banks in coping with AML/CFT regulatory demands. It also explains some of the differences in their respective (different) responses to qualitative probing, which are elaborated upon in the next section (9.2). Table 9.10 is illustrative and makes no pretence of total accuracy in presentation. It compares costs for 2005 (obtained from sample data) with profits for 2004/2005 published by the FSC for the MCs and (using extrapolations based on averages) aggregates costs for 2002-2005, while comparing them with profits for 2001/2002-2004/2005. In other words, the profits figures lag costs by between six months and a year. The same is true for banks. The lack of precision in matching periods is the same for MCs and banks.

However, while accuracy has been sacrificed, the illustrative impact is nevertheless revealing and substantive. Even if cost/profit periods were perfectly matched and published profit data were available for 2005/2006, it is doubtful that the resulting cost/ profit aggregate ratios would be significantly different. The table explains powerfully why MCs (and particularly the smaller more numerous MCs) feel more aggrieved than banks in resenting and opposing the additional cost burdens of AML/CFT regulations being imposed upon them. These costs are eating more heavily into their rapidly thinning profit margins - particularly in the case of small and medium-sized MCs, whose future existence has to be in doubt if the cost/profit $(\mathrm{C} / \mathrm{P})$ ratios in table 9.10 are indicative.

Table 9.10 Incremental AML/CFT costs vs. profits for MCs and banks (US\$ million)

\begin{tabular}{lcccc}
\hline & Year & Costs & Profits-BT & $C / P-\%$ \\
\hline Reporting management companies & $2004 / 05$ & 4.28 & 10.79 & 39.7 \\
& $2001 / 02-04 / 05$ & 12.22 & 37.30 & 32.8 \\
10 largest management companies (extrap.) & $2001 / 02-04 / 05$ & 13.45 & 33.80 & 39.8 \\
Other 75 management companies (extrap.) & $2001 / 02-04 / 05$ & 13.83 & 16.10 & 85.9 \\
Reporting banks & $2004 / 05$ & 2.97 & 71.70 & 4.2 \\
& $2001 / 02-04 / 05$ & 6.61 & 344.80 & 1.9 \\
\hline
\end{tabular}

Sources: BoM Annual Report 2004 for Banks, FSC Annual Report 2005 for MCs: See Tables $9.7 \& 9.8$, above. 
This situation exists because, in providing IFS to GBC licensees, it is the management companies that bear the primary responsibility of establishing complete KYC/DD databases on their 25,750 clients. They share privileged client information in these databases with banks, which then have to duplicate client records and recheck them because - until the seminar - BoM examiners were unwilling to accept information signed off by the FSC without undertaking their own verification and vice versa. After the seminar, the BoM and the FSC agreed to jointly examine ways in which unnecessary duplication of requirements could be minimised, with one regulator accepting what the other has signed off on.

More interestingly, during the seminar it emerged that client information in the same $\mathrm{KYC} / \mathrm{DD}$ databases had to replicated yet again if the same offshore client (or domestic client investing offshore) happened to avail of insurance or stockbroking facilities from insurance brokers and stockbrokers in Mauritius, resulting in four-fold replication of the same client information - even though insurance and stockbrokers are regulated by the FSC. In this electronic age the duplication of so much paper-based data to meet unduly bureaucratic regulatory/supervisory procedural requirements appears extraordinarily costly and inefficient and ought to be remedied swiftly.

\section{Offshore and other banks: analysis of questionnaire responses on costs}

Nine banks returned survey questionnaires before the seminar was held. Further postseminar intervention and follow-up by the MBA resulted in another six banks completing and returning the questionnaires. Of the total of 15 banks eventually responding, all provided quantitative data on their incremental AML/CFT costs. This was an extraordinarily large sample out of a population of 18 banks, of which 11 are engaged in offshore banking. All 11 of these were included in the group that responded with quantitative data, thus resulting in 100 per cent coverage of the banks engaged in providing IFS. Unlike MCs, there was no sub-categorisation of banks as small, medium or large or even as foreign or domestic. The quantitative cost data obtained from banks is depicted in table 9.11, below.

Table 9.11 Incremental AML-CFT costs for banks (US\$)

\begin{tabular}{lrrrr}
\hline Costs incurred by Banks in Mauritius for & Year 2005 & \multicolumn{2}{c}{ Total for 2002-05 } \\
& US\$ & $\%$ & US\$ & $\%$ \\
\hline Establishing internal AML-CFT compliance & & & & \\
machinery & $2,089,500$ & 70.4 & $4,588,700$ & 69.4 \\
KYC-DD database & 499,100 & 16.6 & $1,341,800$ & 20.3 \\
STRs and regulatory/investigative interaction & 385,200 & 13.0 & 682,700 & 10.3 \\
Total costs: & $2,973,800$ & 100.0 & $6,613,200$ & 100.0 \\
Cost per bank & 198,250 & & 440,880 & \\
Extrapolated costs for all 18 banks & $3,568,500$ & & $7,934,400$ & \\
\hline
\end{tabular}


The incremental cost of adjusting to enhanced AML/CFT regulations was \$6.6 million for the 15 reporting banks and is extrapolated (using a simple average) to have been about $\$ 8$ million for all banks. That is less than a third of the costs incurred by the MCs.

The cost for establishing internal AML/CFT compliance machinery was by far the largest cost incurred by banks (70 per cent compared to 50 per cent for MCs), while costs for establishing the KYC/DD database were much lower (20 per cent compared to 42 per cent for MCs) - suggesting that banks (especially foreign banks) had a great deal of help from the head offices. STR and other costs were slightly higher (10 per cent) than for MCs ( 8 per cent). However, within each of these three main categories the proportions accounted for by different sub-categories of costs showed a pretty similar pattern as that for MCs indicated above.

\section{Hidden costs}

The quantifiable costs incurred by MCs represent only direct visible costs. At the seminar (and in annotated responses to questionnaires) many respondents highlighted hidden costs that were difficult to quantify or identify. MCs repeatedly alluded to the real (losing existing clients to other jurisdictions) as well as opportunity costs (clients being discouraged from coming to Mauritius) of lost business because of the rigorous regulatory demands of AML/CFT compliance in Mauritius. The most frequent complaint made by MCs concerned the persistent questioning of clients on beneficial ownership details and the submission of excessive documentary particulars.

Opportunity losses are by definition difficult to measure, though they are not any the less real or less painful to bear because of that deficiency. It is practically impossible to ascribe a monetary figure to the lost business volume and profits that might otherwise have come to the country or the firm had AML regulation not been applied in as draconian a fashion. The study makes no attempt to estimate such losses, but acknowledges from evidence presented informally by many MCs that such losses have been accrued. In private, in privileged discussions with some MCs about their long-standing client relationships, many admitted to referring their more valued clients to correspondent firms or affiliates in other, more tolerant and less rigorous, jurisdictions (Dubai, Singapore and London) when they were unwilling to submit ultimate beneficiary ownership information that was insisted upon by Mauritian regulators.

\section{Total AML/CFT costs: their relation to other performance variables}

The foregoing analysis suggests that the total quantifiable incremental cost to Mauritius (i.e. to regulators and the IFS industry) in the four years 2002-05 of developing and applying the kind of AML/CFT regulatory regime recommended by the FATF and the IFIs was about US\$40 million.

This figure comprised a total cost of $\$ 4.8$ million incurred by public agencies, $\$ 27.3$ million incurred by MCs and a further US $\$ 7.9$ million incurred by banks. One-third of 
the total incremental cost accrued by the public sector was of a non-recurrent (capital) nature. Capital costs for MCs and banks were around a fifth of their total AML/CFT costs. As observed, these costs appear to be understated by around 25-30 per cent on the basis of inconsistencies and anomalies in the questionnaires returned. The real quantifiable costs could be in the order of about US\$50 million, although that is not the figure adopted for analysis.

These sums are not trivial in the context of Mauritius, which had a 2005 Gross National Income (GNI) of US\$6.04 billion. Gross value added in the financial services sector was under 10 per cent of GDP, or US\$605 million. Of this amount, offshore banks were estimated to account for about US\$85 million - i.e. 14 per cent of valueadded by the financial services industry as a whole or about 1.4 per cent of GDP.

Incremental AML/CFT costs of nearly US\$8 million incurred by banks between 2002 and 2005 (an annual average of $\$ 2$ million) in addition to overall compliance costs of \$8-10 million annually, have to be seen in the context of profits (after tax) averaging about $\$ 63$ million annually over the four-year period 2002-2005 for Category 1 (domestic) banks and about US\$65 million annually (before tax) for Category 2 (offshore) banks. They also have to be seen against an annual average wage bill of about US\$35-40 million for domestic banks and around US\$4.5 million for offshore banks.

The costs of MCs of US\$27.3 million (or an annual average of US\$6.8 million) have to be seen in the context of annual turnover of $\$ 37$ million and annual profits for the industry averaging US\$10 million before tax (US\$7 million after tax) over the 20022005 period. The MC industry's net profits (after tax) declined sharply in 2004 to an industry total of under $\$ 2$ million, thanks largely to additional regulatory costs and provisions. The MC industry's annual average AML/CFT costs also have to be seen in the context of an annual average wage bill of around US\$5 million over the period in question, and in the context of total license income derived by the FSC averaging US\$6 million annually of which 80 per cent ( $\$ 4.8$ million) was assumed to be attributable to annual fees payable by GBC and MC licensees. An illustrative picture of AML/ CFT costs relative to these other variables is shown in table 9.12.

\subsection{Qualitative assessment of costs and benefits}

\section{Qualitative assessment of incremental AML/CFT costs}

Apart from the quantitative data on costs provided by the regulators, banks and MCs analysed in the previous section, respondents were also asked to react to qualitative questions and/or statements on which they were asked to express a view along a fivepoint scale (1-5). The low end of the scale (i.e. rating 1) reflected strong agreement, while the high end (rating 5) reflected total disagreement with the statements being made. Qualitative responses to questions on how the IFS industry in Mauritius saw the incremental costs and benefits of the enhanced anti-money laundering/countering financing of terrorism (AML/CFT) regime are scrutinised in this section. It highlights areas in which these responses support, or are inconsistent with, the quantitative 
Table 9.12 AML/CFT costs in perspective

\begin{tabular}{|c|c|c|c|c|c|}
\hline $\begin{array}{l}\text { Indicators } \mathcal{E} \text { variables for comparison } \\
\text { (Amounts in US\$ million; Ratios in \%) }\end{array}$ & 2002 & 2003 & 2004 & 2005 (Est.) & $2002-05$ \\
\hline Incremental AML/CFT costs: total & 8.0 & 8.3 & 9.5 & 14.2 & 40.0 \\
\hline Of which: Public sector institutions & 1.1 & 1.5 & 1.1 & 1.1 & 4.8 \\
\hline Banks & 1.4 & 1.3 & 1.7 & 3.6 & 8.0 \\
\hline Management companies & 5.5 & 5.6 & 6.7 & 9.5 & 27.3 \\
\hline Macro-indicators: GNI at market prices & 4,910 & 5,415 & 5,723 & 6,038 & \\
\hline \multicolumn{6}{|l|}{ Financial intermediation: } \\
\hline Gross Value-Added & 411 & 469 & 555 & 605 & 2,040 \\
\hline Net Value-Added (NVA) & 173 & 206 & 255 & 308 & 942 \\
\hline \multicolumn{6}{|l|}{ IFS Industry: } \\
\hline Gross Value-Added & 45 & 56 & 71 & 85 & 257 \\
\hline Net Value-Added (NVA) & 28 & 33 & 39 & 43 & 143 \\
\hline \multicolumn{6}{|l|}{ Banking Industry: } \\
\hline NVA in domestic banks & 104 & 124 & 163 & 204 & 595 \\
\hline NVA in offshore banks & 21 & 25 & 30 & 33 & 109 \\
\hline \multicolumn{6}{|l|}{ Ratios: } \\
\hline AML/CFT Costs/Net VA in FI (\%) & 4.6 & 4.0 & 3.7 & 4.6 & 4.3 \\
\hline AML/CFT Costs/Net VA in IFS (\%) & 28.5 & 25.2 & 24.4 & 33.1 & 28.0 \\
\hline Banks: Net profits of domestic banks & 56 & 58 & 66 & 73 & 253 \\
\hline Net profits of offshore banks & 55 & 64 & 69 & 74 & 262 \\
\hline \multicolumn{6}{|l|}{ Ratios: } \\
\hline Bank costs/Net VA in all banks (\%) & 1.1 & 0.9 & 0.9 & 1.5 & 1.1 \\
\hline Bank costs/Net VA in offshore banks (\%) & 6.7 & 5.2 & 5.6 & 10.8 & 7.3 \\
\hline Bank costs/Net profits of all banks (\%) & 1.3 & 1.0 & 1.2 & 2.5 & 1.5 \\
\hline Bank costs/Net profits of offshore banks (\%) & 2.2 & 2.0 & 2.4 & 5.0 & 3.1 \\
\hline Management Companies: Turnover (US\$ m) & 29.4 & 33.1 & 41.2 & 45.4 & 149.1 \\
\hline Total expenses & 24.0 & 26.8 & 39.6 & 41.5 & 131.9 \\
\hline Profits $($ after tax $)$ & 5.4 & 6.3 & 1.6 & 3.9 & 17.2 \\
\hline GBC-MC License Fees collected by FSC: & 2.6 & 6.5 & 5.1 & 5.9 & 20.1 \\
\hline \multicolumn{6}{|l|}{ Ratios: } \\
\hline MC costs/GBC-MC license fees (\%) & 210.9 & 85.0 & 132.7 & 161.3 & 135.9 \\
\hline $\mathrm{MC}$ costs/MC turnover (\%) & 18.5 & 16.8 & 16.3 & 21.0 & 18.3 \\
\hline MC costs/MC expenses (\%) & 22.7 & 20.7 & 17.0 & 23.0 & 20.7 \\
\hline $\mathrm{MC}$ costs/MC profits (\%) & 101.0 & 88.1 & 420.1 & 244.9 & 158.6 \\
\hline Memo: employment in: ALL banks & 4,353 & 4,586 & 4,697 & 5,371 & \\
\hline Offshore banks & 512 & 562 & 588 & 643 & \\
\hline MCs & 510 & 600 & 785 & 950 & \\
\hline
\end{tabular}

Sources: FSC Annual Reports 2002 to 2005; BoM Annual Reports 2002 to 2004; National Accounts 2001 to 2005. 
estimates provided to provide a better nuanced picture of reality. How respondents perceived benefits, and whether they felt that intangible benefits (such as reputation) were being translated into tangible benefits (by way of increased turnover, profitability, efficiency, business diversification etc.) is also explored in this section. It concludes with an attempt to establish a clearer perspective on whether net benefits and sidebenefits have been derived from the strengthening of the AML/CFT regulatory and compliance regimes in Mauritius.

Leaving aside any opportunity costs/losses that might have occurred as a consequence of the new AML/CFT regime, MCs and banks were unambiguously clear that the AML/CFT had imposed significant direct costs. In the view of MCs (and small MCs in particular) these costs were onerous and disproportionate to any benefits derived by individual firms operating in the IFS domain, the IFS industry as a whole or the country at large. The views of the banks were more moderate. A few banks expressed views that reflected the strong MC position, while the response of others was more generous and attenuated. The difference is explained partly by the fact that incremental AML/CFT costs for banks are a relatively insignificant proportion of their turnover and net profits. For MCs, the opposite is the case. Also, banks are more accustomed to demanding compliance regimes, whereas up until 2001 MCs were regulated with a lighter, more flexible (and perhaps more appropriate) touch.

The views of regulators were as to be expected, i.e. that the new AML/CFT regime had imposed extra costs but that these were low, tolerable and had to be absorbed by the IFS industry as an essential cost of doing business. Regulators saw themselves as doing the best they could, under formidable external pressure, to adopt new AML/CFT standards that they felt they were not in a position to question or oppose as that would have resulted in blacklisting by the FATF. They did not perceive their actions as being supine, bureaucratic or as imposing excessive cost burdens on the IFS industry. At the seminar the regulators, who were accustomed to a certain level of IFS industry dissatisfaction and complaint, seemed surprised at the depth and strength of feeling that they had perhaps over-stepped the mark and had damaged the competitiveness and profitability of the IFS industry in Mauritius.

The qualitative statements made (and questions asked) about respondents' perceptions of incremental AML/CFT costs were supposed to be modified at the local level by the study for contextual relevance. Given inordinate local delays in sending out questionnaires, and the time pressures under which respondents were told to respond, few such modifications were made. In addition, several questions were omitted, ostensibly to avoid respondent overload, while the lead consultant was unable to review and approve the final version of the questionnaire that was sent out. It appears in retrospect that problems may have arisen with the perceived meaning of some statements/questions and with their interpretation by respondents. Nevertheless, despite these difficulties, enumerated in each case below, the qualitative parts of the questionnaire yielded responses that are worth in-depth exploration. 
There were 12 (amended from the original 20 suggested by the lead consultant) qualitative statements/questions inserted in the questionnaires to amplify and elaborate respondents' views on incremental costs. They were:

1. Has the new AML/CFT regime imposed reasonable additional costs to ensure the reputation of Mauritius as an International Financial Centre (IFC)?

[Note: The problem with this question was that it did not make clear whose costs were being referred to. Were they the costs of the firm asked to respond? Or overall costs for the IFS industry? Or costs incurred by the government and regulators? Or were they all three? In reality respondents might not have known what costs were incurred by anyone other than themselves. Their responses reflect that reality.]

2. Has the new AML/CFT regime imposed reasonable additional costs on the official regulators of the financial system (i.e. BoM, the FSC etc.)?

[Note: The note above also applies in this instance. Unless respondents were aware of costs incurred by regulators, their impressions could only have been speculative.]

3. Has the new AML/CFT regime imposed excessive additional costs for financial regulation in Mauritius (i.e. disproportionate to any conceivable benefit)?

[Note: In addition to the complications noted above, this is a leading question that might have reinforced respondent biases in a particular direction.]

4. The new AML/CFT regime has imposed disproportionately high costs on our firm compared to any likely benefits that might accrue to us.

[Note: This direct statement does not require respondents to make judgements based on information they do not have. Answers were clearer and less confused for that reason. The same is true for the final eight statements/questions.]

5. The new AML/CFT regime has imposed additional costs that are so high that our firm is considering exiting the IFS business.

6. The new AML/CFT regime has made excessive demands on the capabilities of our personnel in meeting new compliance requirements.

7. The new AML/CFT regime has required us to increase our staff complement substantially.

8. The new AML/CFT regime has required us to retrain front line staff dealing with customers.

9. The new AML/CFT regime has required us to retrain back office staff dealing with $\mathrm{KYC} / \mathrm{DD}$ compliance and with regulators.

10. The new AML/CFT regime has required us to invest in additional new IT systems and retraining for staff handling these systems.

11. The new AML/CFT regime has required us to spend far more on systems, training and staff than was necessary for regular business growth. 
12. The new AML/CFT regime has diverted our attention from other more important matters concerning the diversification and growth of our IFS business [Note: In the version sent out this statement was garbled.]

\section{Statement-by-statement analysis of respondents' qualitative views on costs}

The pattern of responses from management companies and banks to each of these questions is shown in tabular form below and accompanied by a discussion of the responses.

Has the new AML-CFT regime imposed reasonable additional costs to ensure the reputation of Mauritius as an International Financial Centre (IFC)?

\begin{tabular}{|c|c|c|c|c|c|c|c|}
\hline \multirow[t]{2}{*}{ Responses from } & & & \multirow{2}{*}{$\begin{array}{c}\text { AS } \\
1\end{array}$} & \multirow{2}{*}{$\begin{array}{l}A \\
2\end{array}$} & \multirow{2}{*}{$\begin{array}{c}\text { No opinion } \\
(\%) \\
3\end{array}$} & \multirow{2}{*}{$\begin{array}{l}D \\
4\end{array}$} & \multirow{2}{*}{$\begin{array}{c}D S \\
5\end{array}$} \\
\hline & & & & & & & \\
\hline \multirow[t]{4}{*}{ Management companies: } & Small & [ 21 ] & 4.8 & 42.9 & 28.6 & 23.7 & 0.0 \\
\hline & Medium & {$[4]$} & 0.0 & 0.0 & 75.0 & 0.0 & 25.0 \\
\hline & Large & [ 7 ] & 14.3 & 28.6 & 14.3 & 42.9 & 0.0 \\
\hline & Total & {$[32$ ] } & 6.7 & 36.7 & 30.0 & 23.3 & 3.3 \\
\hline Banks: & [ 15] & 33.3 & 33.3 & 13.3 & 20.0 & 0.0 & \\
\hline
\end{tabular}

AS 1= Agree Strongly; A 2= Agree; 3= No Clear Opinion; D 4= Disagree; DS 5= Disagree Strongly

Although the question is imprecise, with a caveat that created some confusion, the pattern of responses from MCs clusters between 2 and 4 on the rating scale (i.e. agree, no opinion and disagree), and between 1 and 3 for banks. The percentage of views at either end of the scale is insignificant. A third of all banks agreed strongly that the costs imposed had been reasonable to safeguard the reputation of Mauritius. Large and small MCs provided a pattern of answers within the same 2-4 rating cluster; but as many large MCs disagree with the statement as agree, while smaller MCs agree more than disagree. Medium-sized MCs indicate a response pattern skewed by too small a sample size. There was too high a proportion of 'no opinions' for comfort ${ }^{4}$. Discussions at the seminar made it clear that, if the question had not included the caveat ('to ensure the reputation of Mauritius as an IFC'), the proportion of answers for MCs would have shifted to 4-5 on the rating scale (i.e. disagree and strongly disagree that the additional costs were 'reasonable'). However, the proportion would have remained the same for banks. The pattern of responses reflected above does not accord with the quantitative information (and accompanying annotations) provided. These suggest that all MCs, regardless of size, felt that the additional costs were unreasonably high although that applied to costs incurred by firms, rather than the expenditures made to safeguard the reputation of Mauritius. The above responses do accord with the quantitative information and views provided by banks. 
Has the new AML/CFT regime imposed reasonable additional costs on the official regulators of the financial system?

\begin{tabular}{|c|c|c|c|c|c|c|c|c|}
\hline \multirow[t]{2}{*}{ Responses from } & & & AS & $A$ & $\begin{array}{c}\text { No Opinion } \\
(\%)\end{array}$ & $D$ & $D S$ & \multirow{2}{*}{$\begin{array}{c}N S \\
(\%) \\
6\end{array}$} \\
\hline & & & 1 & 2 & 3 & 4 & 5 & \\
\hline \multirow[t]{4}{*}{ Management companies: } & Small & {$[21]$} & 9.5 & 23.8 & 38.1 & 19.0 & 4.8 & 4.8 \\
\hline & Medium & [ 4 ] & 25.0 & 0.0 & 50.0 & 0.0 & 25.0 & \\
\hline & Large & [ 7 ] & 0.0 & 28.6 & 42.9 & 14.3 & 14.3 & \\
\hline & Total & [ 32 ] & 9.3 & 21.9 & 40.6 & 15.6 & 9.3 & 3.1 \\
\hline Banks: & {$[15]$} & 20.0 & 13.3 & 53.3 & 13.3 & 0.0 & & \\
\hline
\end{tabular}

AS 1= Agree Strongly; A 2= Agree; $3=$ No Clear Opinion; D 4= Disagree; DS 5= Disagree Strongly; NS: Not Specified

The key feature of responses to this question for MCs and banks is the number of 'no opinions', which is perhaps understandable given that respondents were largely unaware of what the costs incurred by regulators were. However, of those who did have an opinion, the number of MCs in agreement with the view that 'costs were reasonable for regulators' marginally outweighed those that disagreed (by 31 per cent to 25 per cent) while, in the case of banks, those that agreed significantly outweighed those that disagreed (43 per cent to 13 per cent). Those opinions tend to support the view of regulators themselves that their costs were reasonable if not low.

Has the new AML/CFT regime imposed excessive additional costs for financial regulation in Mauritius (i.e. disproportionate to any conceivable benefit)?

\begin{tabular}{|c|c|c|c|c|c|c|c|}
\hline \multirow[t]{2}{*}{ Responses from } & & & \multirow{2}{*}{$\begin{array}{c}\text { AS } \\
1\end{array}$} & \multirow[t]{2}{*}{$A$} & \multirow{2}{*}{$\begin{array}{c}\text { No opinion } \\
(\%) \\
3\end{array}$} & \multirow{2}{*}{$\begin{array}{l}D \\
4\end{array}$} & \multirow{2}{*}{$\begin{array}{c}\text { DS } \\
5\end{array}$} \\
\hline & & & & & & & \\
\hline \multirow[t]{4}{*}{ Management companies: } & Small & {$[21]$} & 14.3 & 23.8 & 33.3 & 19.0 & 9.6 \\
\hline & Medium & [4] & 50.0 & 0.0 & 25.0 & 25.0 & 0.0 \\
\hline & Large & [ 7 ] & 14.3 & 42.9 & 14.3 & 28.6 & 0.0 \\
\hline & Total & [ 32 ] & 18.8 & 25.0 & 28.1 & 21.9 & 6.2 \\
\hline Banks: & {$[15]$} & 6.7 & 26.7 & 13.3 & 46.7 & 6.7 & \\
\hline
\end{tabular}

AS 1= Agree Strongly; A 2= Agree; 3= No Clear Opinion; D 4= Disagree; DS 5= Disagree Strongly

This was included as a test question to cross-check against responses to the previous question. The pattern of responses was inconsistent in the case of MCs, but consistent in the case of banks. The one revealing inconsistency in the case of both banks and MCs was that the proportion of 'don't knows or no opinions' should have been at least as high as for the previous question, given that respondents did not know what the costs of regulators were. However, they were much lower. Some 44 per cent of MCs 
agreed that costs for financial regulation were excessive whereas for the previous question just 25 per cent had disagreed with the view that the same costs were reasonable. The two proportions should have been more or less the same. About 28 per cent of MCs disagreed that costs were excessive, which seemed to reconcile with the view expressed by 31 per cent of them for the previous question suggesting that costs were reasonable. The $\mathrm{MC}$ view was somewhat reversed for the banks, of which a third agreed that costs were excessive while over 52 per cent disagreed. The inconsistencies revealed in the responses to the above two questions indicate how sensitive a survey of this nature can be to the particular words used to evoke a response.

The new AML/CFT regime has imposed disproportionately high costs on our firm compared to any likely benefits that might accrue to us.

\begin{tabular}{|c|c|c|c|c|c|c|c|}
\hline \multirow[t]{2}{*}{ Responses from } & & & \multirow{2}{*}{$\begin{array}{c}\text { AS } \\
1\end{array}$} & \multirow{2}{*}{$\begin{array}{l}A \\
2\end{array}$} & \multirow{2}{*}{$\begin{array}{c}\text { No opinion } \\
(\%) \\
3\end{array}$} & \multirow{2}{*}{$\begin{array}{l}D \\
4\end{array}$} & \multirow{2}{*}{$\begin{array}{r}D S \\
5\end{array}$} \\
\hline & & & & & & & \\
\hline \multirow[t]{4}{*}{ Management companies: } & Small & [ 21 ] & 23.8 & 28.6 & 19.0 & 19.0 & 9.6 \\
\hline & Medium & [4] & 50.0 & 0.0 & 25.0 & 25.0 & 0.0 \\
\hline & Large & {$[7]$} & 0.0 & 57.1 & 14.3 & 28.6 & 0.0 \\
\hline & Total & [ 32 ] & 21.9 & 31.2 & 18.8 & 21.9 & 6.2 \\
\hline Banks: & {$[15]$} & 6.7 & 26.7 & 0.0 & 53.3 & 13.3 & \\
\hline
\end{tabular}

AS 1 = Agree Strongly; A 2 = Agree; 3 = No Clear Opinion; D 4 = Disagree; DS 5 = Disagree Strongly

The qualitative responses to this particular statement (which is clear and unambiguous) appear to be misaligned with the views expressed by MCs in their quantitative responses and more vociferously during the seminar. It may suggest a problem with statement misinterpretation by junior personnel, who may have been too inexperienced to understand their business, or the meaning of their response. That was clearly not the case for banks, all of which had an opinion with the majority (two-thirds) being clearly of the view that their costs were not disproportionately high. It seems almost inconceivable (especially in view of the seminar discussion on this subject) that nearly a fifth of MCs had no opinion on whether the incremental cost burden imposed by new AML/CFT regulations was disproportionately high or not, when all their other responses suggest strongly that they had. It was odd, in the light of other responses (see below) and the discussions at the seminar, that only 53 per cent of MCs indicated that costs were too high, while 28 per cent disagreed with that view. The reactions of MCs at the seminar suggested a figure closer to 100 per cent believing that costs were too high. That picture can only be reconciled if the respondents who had expressed no opinion (19 per cent) were aligned with the small majority (53 per cent) who thought costs were too high. It is of course possible, but unlikely, that MCs disagreeing with that view were not at the seminar. 
The new AML/CFT regime has imposed additional costs that are so high that our firm is considering exiting the IFS business.

\begin{tabular}{|c|c|c|c|c|c|c|c|}
\hline \multirow[t]{2}{*}{ Responses from } & & & \multirow{2}{*}{$\begin{array}{c}\text { AS } \\
1\end{array}$} & \multirow{2}{*}{$\begin{array}{l}A \\
2\end{array}$} & \multirow{2}{*}{$\begin{array}{c}\text { No opinion } \\
(\%) \\
3\end{array}$} & \multirow{2}{*}{$\begin{array}{l}D \\
4\end{array}$} & \multirow{2}{*}{$\begin{array}{c}D S \\
5\end{array}$} \\
\hline & & & & & & & \\
\hline \multirow[t]{4}{*}{ Management companies: } & Small & [ 21 ] & 0.0 & 4.8 & 23.8 & 28.5 & 42.9 \\
\hline & Medium & {$[4]$} & 0.0 & 0.0 & 0.0 & 50.0 & 50.0 \\
\hline & Large & {$[7]$} & 0.0 & 0.0 & 0.0 & 0.0 & 100.0 \\
\hline & Total & [ 32 ] & 0.0 & 3.1 & 15.6 & 25.0 & 56.3 \\
\hline Banks: & {$[15]$} & 0.0 & 0.0 & 13.3 & 26.7 & 60.0 & \\
\hline
\end{tabular}

AS 1= Agree Strongly; A 2= Agree; $3=$ No Clear Opinion; D 4= Disagree; DS 5= Disagree Strongly

This again was a test statement (carrying the previous statement to an extreme) to gauge the degree to which the IFS industry felt overburdened by the incremental cost of the post-2002 AML/CFT regime. The response was unambiguous. Over 81 per cent of MCs (indeed 100 per cent of medium-sized and large MCs) and 87 per cent of banks disagreed that incremental costs were so high as to prompt them to consider exiting the IFS business. Indeed only one small MC agreed with the proposition. Strangely, five small MCs had no opinion on even as extreme a statement, nor did two banks.

Questions/statements relating to staff and staff costs: The following four statements were designed to draw respondents out on the staffing implications and staff costs of coping with the new AML/CFT regime. The responses were as might have been expected, with increasingly strong views being expressed about pressures on staff in reaction to more specific statements relating to training front and back office (including compliance) staff

The new AML/CFT regime has made excessive demands on the capabilities of our personnel in meeting new compliance requirements.

\begin{tabular}{|c|c|c|c|c|c|c|c|}
\hline \multicolumn{3}{|l|}{ Responses from } & \multirow{2}{*}{$\begin{array}{c}\text { AS } \\
1\end{array}$} & \multirow{2}{*}{$\begin{array}{l}A \\
2\end{array}$} & \multirow{2}{*}{$\begin{array}{c}\text { No opinion } \\
(\%) \\
3\end{array}$} & \multirow{2}{*}{$\begin{array}{l}D \\
4\end{array}$} & \multirow{2}{*}{$\begin{array}{c}D S \\
5\end{array}$} \\
\hline & & & & & & & \\
\hline \multirow[t]{4}{*}{ Management companies: } & Small & [ 21 ] & 19.0 & 28.6 & 14.6 & 28.6 & 9.5 \\
\hline & Medium & [4] & 50.0 & 0.0 & 25.0 & 25.0 & 0.0 \\
\hline & Large & [ 7 ] & 42.9 & 28.6 & 0.0 & 14.3 & 14.3 \\
\hline & Total & [ 32 ] & 28.1 & 25.0 & 12.5 & 25.0 & 9.4 \\
\hline Banks: & [ 15] & 6.7 & 33.3 & 6.7 & 46.7 & 6.7 & \\
\hline
\end{tabular}

AS 1= Agree Strongly; A 2= Agree; 3= No Clear Opinion; D 4= Disagree; DS 5= Disagree Strongly 
The new regime has required us to increase our staff complement substantially.

\begin{tabular}{|c|c|c|c|c|c|c|c|}
\hline \multirow[t]{2}{*}{ Responses from } & & & \multirow{2}{*}{$\begin{array}{c}\text { AS } \\
1\end{array}$} & \multirow{2}{*}{$\begin{array}{l}A \\
2\end{array}$} & \multirow{2}{*}{$\begin{array}{c}\text { No opinion } \\
(\%) \\
3\end{array}$} & \multirow{2}{*}{$\begin{array}{l}D \\
4\end{array}$} & \multirow{2}{*}{$\begin{array}{c}D S \\
5\end{array}$} \\
\hline & & & & & & & \\
\hline \multirow{4}{*}{ Management companies: } & Small & [ 21] & 14.3 & 57.1 & 14.3 & 14.3 & 0.0 \\
\hline & Medium & [ 4] & 50.0 & 25.0 & 0.0 & 25.0 & 0.0 \\
\hline & Large & [ 7 ] & 71.4 & 14.3 & 0.0 & 14.3 & 0.0 \\
\hline & Total & [ 32 ] & 31.2 & 43.8 & 9.4 & 15.6 & 0.0 \\
\hline Banks: & {$[15]$} & 0.0 & 46.7 & 20.0 & 33.3 & 0.0 & \\
\hline
\end{tabular}

AS 1= Agree Strongly; A 2= Agree; 3= No Clear Opinion; D 4= Disagree; DS 5= Disagree Strongly

The new regime has required us to retrain front line staff dealing with customers.

\begin{tabular}{|c|c|c|c|c|c|c|c|}
\hline \multirow[t]{2}{*}{ Responses from } & & & \multirow{2}{*}{$\begin{array}{c}\text { AS } \\
1\end{array}$} & \multirow{2}{*}{$\begin{array}{l}A \\
2\end{array}$} & \multirow{2}{*}{$\begin{array}{c}\text { No opinion } \\
(\%) \\
3\end{array}$} & \multirow{2}{*}{$\begin{array}{l}D \\
4\end{array}$} & \multirow{2}{*}{$\begin{array}{c}\text { DS } \\
5\end{array}$} \\
\hline & & & & & & & \\
\hline \multirow[t]{4}{*}{ Management companies: } & Small & [ 21 ] & 19.0 & 57.2 & 9.5 & 9.5 & 4.8 \\
\hline & Medium & [4] & 75.0 & 25.0 & 0.0 & 0.0 & 0.0 \\
\hline & Large & [ 7 ] & 57.1 & 58.6 & 0.0 & 14.3 & 0.0 \\
\hline & Total & [32] & 34.4 & 46.9 & 6.3 & 9.3 & 3.1 \\
\hline Banks: & {$[15]$} & 53.3 & 33.3 & 0.0 & 13.3 & 0.0 & \\
\hline
\end{tabular}

AS 1= Agree Strongly; A 2= Agree; 3= No Clear Opinion; D 4= Disagree; DS 5= Disagree Strongly

The new regime has required us to retrain back office staff dealing with KYC/DD compliance and with regulators.

\begin{tabular}{|c|c|c|c|c|c|c|c|}
\hline \multirow[t]{2}{*}{ Responses from } & & & \multirow{2}{*}{$\begin{array}{c}\text { AS } \\
1\end{array}$} & \multirow{2}{*}{$\begin{array}{l}A \\
2\end{array}$} & \multirow{2}{*}{$\begin{array}{c}\text { No opinion } \\
(\%) \\
3\end{array}$} & \multirow{2}{*}{$\begin{array}{l}D \\
4\end{array}$} & \multirow{2}{*}{$\begin{array}{c}\text { DS } \\
5\end{array}$} \\
\hline & & & & & & & \\
\hline \multirow[t]{4}{*}{ Management Companies: } & Small & [ 21 ] & 33.3 & 42.9 & 23.8 & 0.0 & 0.0 \\
\hline & Medium & [ 4 ] & 75.0 & 25.0 & 0.0 & 0.0 & 0.0 \\
\hline & Large & [ 7 ] & 42.9 & 42.9 & 0.0 & 14.3 & 0.0 \\
\hline & Total & [ 32 ] & 40.6 & 40.6 & 15.6 & 3.2 & 0.0 \\
\hline Banks: & [ 15 ] & 53.3 & 33.3 & 0.0 & 13.3 & 0.0 & \\
\hline
\end{tabular}

AS 1= Agree Strongly; A 2= Agree; $3=$ No Clear Opinion; D 4= Disagree; DS $5=$ Disagree Strongly

As can be seen from the above pattern of responses, banks were evenly divided in their views about whether their extant staff resources had been overstretched, or needed to be increased, because of AML/CFT demands when asked about the issue in general 
terms. However, they reacted more strongly when asked specific questions about front and back office staff having to be retrained (presumably with accompanying costs).

An increasing majority of MCs felt, on the other hand, that their staff resources had been overstretched ( 53 per cent), had needed to be increased substantially ( 75 per cent), and had to be retrained (81 per cent for both front and back office staff) because of additional AML/CFT related work. This view was substantiated by their quantitative data on overall costs, in which staff accounted for a significant proportion of total additional costs.

While banks had the same retraining needs (and costs), they did not feel quite as strongly as MCs about the need to increase staff to alleviate overstretching. Only 40 per cent of banks thought their staff had been overstretched by additional AML/ CFT demands and just under a half had to increase their staff resources for this purpose. Again, the qualitative view is supported by the quantitative evidence on this particular issue.

The new AML/CFT regime has required us to invest in additional new IT systems and retraining for staff handling these systems.

\begin{tabular}{|c|c|c|c|c|c|c|c|}
\hline \multirow[t]{2}{*}{ Responses from } & & & \multirow{2}{*}{$\begin{array}{c}\text { AS } \\
1\end{array}$} & \multirow{2}{*}{$\begin{array}{l}A \\
2\end{array}$} & \multirow{2}{*}{$\begin{array}{c}\text { No opinion } \\
(\%) \\
3\end{array}$} & \multirow{2}{*}{$\begin{array}{l}D \\
4\end{array}$} & \multirow{2}{*}{$\begin{array}{c}D S \\
5\end{array}$} \\
\hline & & & & & & & \\
\hline \multirow[t]{4}{*}{ Management companies: } & Small & [ 21$]$ & 19.0 & 33.3 & 19.0 & 14.3 & 14.3 \\
\hline & Medium & [ 4 ] & 50.0 & 0.0 & 0.0 & 50.0 & 0.0 \\
\hline & Large & [ 7 ] & 14.3 & 56.1 & 14.3 & 0.0 & 14.3 \\
\hline & Total & [ 32 ] & 21.9 & 34.4 & 15.6 & 15.6 & 12.5 \\
\hline Banks: & {$[15]$} & 13.3 & 60.0 & 13.3 & 6.7 & 6.7 & \\
\hline
\end{tabular}

AS 1= Agree Strongly; A 2= Agree; 3= No Clear Opinion; D 4= Disagree; DS 5= Disagree Strongly

The new AML/CFT regime has required us to spend far more on systems, training and staff than was necessary for regular business growth.

\begin{tabular}{|c|c|c|c|c|c|c|c|}
\hline \multicolumn{3}{|l|}{ Responses from } & $\begin{array}{c}\text { AS } \\
1\end{array}$ & $\begin{array}{l}A \\
2\end{array}$ & $\begin{array}{c}\text { No opinion } \\
(\%) \\
3\end{array}$ & $\begin{array}{l}D \\
4\end{array}$ & $\begin{array}{c}D S \\
5\end{array}$ \\
\hline \multirow[t]{4}{*}{ Management companies: } & Small & [ 21 ] & 23.8 & 47.6 & 14.3 & 14.3 & 0.0 \\
\hline & Medium & [ 4] & 50.0 & 50.0 & 0.0 & 0.0 & 0.0 \\
\hline & Large & {$[7]$} & 57.1 & 28.6 & 0.0 & 14.3 & 0.0 \\
\hline & Total & [ 32 ] & 34.3 & 43.7 & 9.4 & 12.5 & 0.0 \\
\hline Banks: & [ 15] & 13.3 & 33.3 & 6.7 & 46.7 & 0.0 & \\
\hline
\end{tabular}

AS 1= Agree Strongly; A 2= Agree; 3= No Clear Opinion; D 4= Disagree; DS 5= Disagree Strongly 
The above two statements were aimed at drawing out $\mathrm{MC} / \mathrm{bank}$ views on incremental IT systems expenditures necessitated by the enhanced AML/CFT regime. A majority (56 per cent) of MCs felt that they had been required to make significant additional investments in IT systems as a result of increasingly complicated AML/CFT compliance demands. However, a fairly significant proportion (44 per cent) had either no view or disagreed. Banks were more emphatic about this than MCs, with more than 73 per cent believing that they had to make such investments. However, a higher proportion of MCs (78 per cent) felt they had to spend disproportionately more on such systems than was necessary than banks (46.6 per cent), with the majority of banks (53 per cent) having no opinion or disagreeing.

The quantitative evidence does not fully reflect this divided view. Despite half of all respondents believing that additional investment in IT systems was significant, the quantitative evidence was surprising. It showed how little the IFS industry in Mauritius (relative to jurisdictions elsewhere) has spent on increasing or upgrading IT systems (hardware and software) to meet increased AML/CFT compliance, and to maintain much larger databases of confidential client information that has to be instantly referred to, cross-matched and exchanged. If the qualitative data were to be reconciled with the quantitative data, the only reasonable conclusion might be that respondents had either understated their incremental IT costs or they had not incurred really high IT costs as yet. (Note: This seems to be true of the FSC, the FIU and the BoM, all of which in their most recent annual reports indicate that they will need to make substantial new IT investments in the coming year to cope with substantially increased regulatory/supervision workloads.)

The new AML/CFT regime has diverted our attention from other more important matters concerning the diversification and growth of our IFS business

\begin{tabular}{|c|c|c|c|c|c|c|c|}
\hline \multirow[t]{2}{*}{ Responses from } & & & \multirow{2}{*}{$\begin{array}{c}\text { AS } \\
1\end{array}$} & \multirow{2}{*}{$\begin{array}{l}A \\
2\end{array}$} & \multirow{2}{*}{$\begin{array}{c}\text { No opinion } \\
(\%) \\
3\end{array}$} & \multirow{2}{*}{$\begin{array}{l}D \\
4\end{array}$} & \multirow{2}{*}{$\begin{array}{c}D S \\
5\end{array}$} \\
\hline & & & & & & & \\
\hline \multirow[t]{4}{*}{ Management companies: } & Small & [ 21 ] & 38.1 & 23.8 & 33.3 & 4.8 & 0.0 \\
\hline & Medium & {$[4]$} & 50.0 & 0.0 & 25.0 & 25.0 & 0.0 \\
\hline & Large & {$[7]$} & 28.6 & 14.2 & 28.6 & 0.0 & 28.6 \\
\hline & Total & {$[32$ ] } & 37.5 & 18.8 & 31.1 & 6.3 & 6.3 \\
\hline Banks: & [ 15] & 6.7 & 26.7 & 20.0 & 26.7 & 20.0 & \\
\hline
\end{tabular}

AS 1= Agree Strongly; A 2= Agree; 3= No Clear Opinion; D 4= Disagree; DS 5= Disagree Strongly

Finally, over 56 per cent of MCs felt that coping with the new AML/CFT regime had diverted their attention from more important matters concerning their growth and diversification. However, only a third of banks concurred. A significant proportion of both groups expressed no opinion. It was clear from the seminar that the difference in views between banks and MCs was because: (a) banks had taken additional AML/CFT 
demands in their stride partly because they were used to greater compliance demands; but also (b) when it came to providing IFS to licensed GBC clients, it was the MCs that took the brunt of dealing with the additional KYC/DD information load which they later shared with banks.

In an overall sense the qualitative responses broadly supported the quantitative returns provided, albeit with a few inconsistencies and anomalies that suggest the need for further exploration of the issues they raise in a future study.

\section{Qualitative assessment of incremental AML/CFT benefits}

A perspective on 'benefits': Before this study was launched in Mauritius, preliminary discussions were held by the lead and local consultants with MCs and banks to determine whether it might be possible to identify any tangible benefits that had been derived from enhancing the AML/CFT regulatory and compliance regime. It was clear from those discussions that it would be difficult to identify, and almost impossible to quantify, any tangible incremental benefits resulting from the new regime. Regulators and policy-makers felt, however, that one obvious tangible benefit was Mauritius's ability to stay in the offshore financial centre business as a consequence of adopting the new regime. If one takes that as a serious rather than self-justifying proposition, and attempts to put a value to it then, as the estimates in table 9.12 suggest, the benefits are large. Staying in business has resulted in:

- Net value addition by the IFS industry amounting to an aggregate US\$143 million between 2002 and 2005 (an average of about US\$36 million annually);

- Aggregate net profits of offshore banks amounting to US\$262 million (US\$63 million pa);

- Aggregate net profits of MCs amounting to US\$17.2 million (or US\$4.3 million pa);

- GBC-MC license fees aggregating US\$20 million (US\$5 million pa) - although these might be seen as a benefit to Mauritius, they represent a cost to the IFS industry although there is a positive net balance-of-payments effect when fees are paid by offshore clients; and

- Net employment of about 1,400 people with an annual average wage bill of about US\$15 million (again perhaps a benefit to Mauritius, but a cost to the IFS industry and difficult to ascertain how much of this employment can be counted as a net benefit).

That provides an estimate of total benefits amounting to US\$457 million over the fouryear period, or an average of US\$114 million per annum. However, that figure includes some double-counting because an element of net financial profits would be captured in net economic value addition and in employment figures as well. Discounting that complication for argument's sake, and not trying to net it out, the volume of benefits seen against aggregate costs of US $\$ 40$ million for the new AML/CFT regime - make 
net benefits amounting to US $\$ 417$ million look quite substantial, with a cost/benefit ratio of over 1 -to-11.

Can the assertion of regulators and policy-makers - i.e. that the main benefit was that the imposed AML/CFT regime allowed Mauritius to stay in the offshore financial centre business - be taken seriously for the purposes of this study? As far as this study is concerned, that would stretch credulity to its limits. Put simplistically, the proposition is tantamount to someone threatening to end your existence if you do not accede to their demands, regardless of cost. You then pay the cost without calculating it in advance (assuming you can afford it) for the 'benefit' of staying alive. Then you count the income you receive from being alive as a benefit without counting the threat itself (only the blackmail part of it) as a cost. However, what if the threat had not arisen in the first place, because you did nothing to arouse it, although some other party might have? It was an artificial threat contrived by other parties determined to deal with perceived threats to themselves in ways that protected their perceived interests regardless of the cost to your legitimate existential and business interests. Under those circumstances, can succumbing to what is effectively blackmail be considered a legitimate benefit?

Putting it differently, before the new AML/CFT regime was introduced, Mauritius could not, under any circumstances, have been portrayed as being poorly regulated even by the standards of regulation in many developed jurisdictions. Arguably, even today, regulation in some of these jurisdictions is more flexible and accommodating than in Mauritius. The case of Mauritius was not that of a poorly-regulated, small OFC jurisdiction, vulnerable to predation by criminal elements openly abusing the financial system. Prior to 1992 Mauritius had a thriving IFS industry whose gross benefits were almost the same as in 2005/6, but with much lower regulatory costs.

Set against those circumstances, the study takes the view that the incremental net benefits of enhanced AML/CFT legislation are virtually zero. They have added almost nothing of value in protecting Mauritius' legitimate interests. Allowing generously that they might have helped in keeping criminality in financial transactions further at bay, it is difficult to see any incremental benefit because even the previous regulatory regime did that quite adequately. If the new regime is 'tighter' it is impossible to assess by how much or even how much such tightening has benefited Mauritius. The new regime certainly is more process driven, requires more documentation - some of which may (as suggested at the seminar) be useless. It does not necessarily enable MCs, banks or regulators to 'know-their-clients' any better, nor to discern their motives more transparently, through due diligence - than they did before.

Those circumstances notwithstanding, and taking into account the view of the IFS industry that any benefits that might have been derived would be intangible (i.e. reputational) and could not be quantified, the questionnaires incorporated 15 questions aimed at eliciting a qualitative 'feel' for what unquantifiable benefits might still have accrued from the new regime. These statements (listed below) and the responses 
to them are analysed in the paragraphs that follow. The statements to which reactions on 'benefits' were sought were:

Has the new AML/CFT regime:

- Strengthened overall financial system regulation in Mauritius?

- Enhanced the reputation of Mauritius as an international financial centre?

- Increased the competitiveness of Mauritius compared to other offshore centres?

After new KYC/DD compliance requirements were introduced, what has been the impact on:

- Your firm's overall business, i.e. by what percentage has it increased/decreased?

- Your firm's total revenue from IFS activity?

- Your firm's profits from IFS activity?

- Staff efficiency/productivity in your firm?

- Client and source country diversification?

- Access to foreign markets?

- Your firm's product/services diversification

- Increased competitiveness of Mauritius as an IFC?

- Increased competitiveness of your firm in the IFS Industry?

- Improving your firm's technological capacity?

- Improving your firm's overall knowledge base in providing global IFS?

- Increasing the profitability of your firm from improved risk management?

The pattern of responses is portrayed below, along with an analysis of what they imply.

Has the new AML/CFT regime strengthened financial regulation in Mauritius?

\begin{tabular}{|c|c|c|c|c|c|c|c|}
\hline \multirow[t]{2}{*}{ Responses from } & & & \multirow{2}{*}{$\begin{array}{c}\text { AS } \\
1\end{array}$} & \multirow{2}{*}{$\begin{array}{l}A \\
2\end{array}$} & \multirow{2}{*}{$\begin{array}{c}\text { No opinion } \\
(\%) \\
3\end{array}$} & \multirow{2}{*}{$\begin{array}{l}D \\
4\end{array}$} & \multirow{2}{*}{$\begin{array}{c}D S \\
5\end{array}$} \\
\hline & & & & & & & \\
\hline \multirow{4}{*}{ Management companies: } & Small & [ 21 ] & 23.8 & 28.6 & 38.0 & 4.8 & 4.8 \\
\hline & Medium & [ 4] & 50.0 & 25.0 & 25.0 & 0.0 & 0.0 \\
\hline & Large & [ 7 ] & 42.9 & 28.6 & 28.6 & 0.0 & 0.0 \\
\hline & Total & [ 32 ] & 31.3 & 28.1 & 34.4 & 3.1 & 3.1 \\
\hline Banks: & {$[15]$} & 40.0 & 40.0 & 20.0 & 0.0 & 0.0 & \\
\hline
\end{tabular}

AS 1= Agree Strongly; A 2= Agree; 3= No Clear Opinion; D 4= Disagree; DS 5= Disagree Strongly 
An overwhelming majority ( 80 per cent) of banks felt that the new regime had strengthened overall financial system regulation in Mauritius. A slightly lower but clear majority (59 per cent) of MCs felt the same way, although the majority was higher ( 75 per cent) among the larger and the medium-sized MCs. Oddly, over a third of MCs and a fifth of banks had no opinion on that question, while an insignificant minority of MCs (the smaller ones) but no banks, actually disagreed.

Has the new AML/CFT regime enhanced the reputation of Mauritius as an international financial centre?

\begin{tabular}{|c|c|c|c|c|c|c|c|}
\hline \multirow[t]{2}{*}{ Responses from } & & & \multirow{2}{*}{$\begin{array}{c}\text { AS } \\
1\end{array}$} & \multirow{2}{*}{$\begin{array}{l}A \\
2\end{array}$} & \multirow{2}{*}{$\begin{array}{c}\text { No opinion } \\
(\%) \\
3\end{array}$} & \multirow{2}{*}{$\begin{array}{l}D \\
4\end{array}$} & \multirow{2}{*}{$\begin{array}{c}D S \\
5\end{array}$} \\
\hline & & & & & & & \\
\hline \multirow[t]{4}{*}{ Management companies: } & Small & [ 21 ] & 23.8 & 42.9 & 14.3 & 19.0 & 0.0 \\
\hline & Medium & {$[4]$} & 25.0 & 50.0 & 25.0 & 0.0 & 0.0 \\
\hline & Large & [ 7 ] & 14.3 & 57.1 & 28.6 & 0.0 & 0.0 \\
\hline & Total & [ 32 ] & 21.9 & 46.9 & 18.9 & 12.3 & 0.0 \\
\hline Banks: & {$[15]$} & 33.3 & 33.3 & 26.7 & 6.7 & 0.0 & \\
\hline
\end{tabular}

AS 1= Agree Strongly; A 2= Agree; 3= No Clear Opinion; D 4= Disagree; DS 5= Disagree Strongly

The pattern of responses to this complementary question supports the views expressed in the previous one. Nearly 69 per cent of MCs and 67 per cent of banks agreed that the reputation of Mauritius had been enhanced as a result of introducing the new AML/ CFT regime. About 19 per cent of MCs had no view and only 12 per cent disagreed. The respective proportions for the banks were 27 per cent (no view) and 7 per cent (disagreed). The industry response was therefore unambiguous and tallied with that of regulators.

Has the new AML/CFT regime increased the competitiveness of Mauritius compared to other offshore financial centres?

\begin{tabular}{|c|c|c|c|c|c|c|c|}
\hline \multirow[t]{2}{*}{ Responses from } & & & \multirow{2}{*}{$\begin{array}{c}\text { AS } \\
1\end{array}$} & \multirow{2}{*}{$\begin{array}{l}A \\
2\end{array}$} & \multirow{2}{*}{$\begin{array}{c}\text { No opinion } \\
(\%) \\
3\end{array}$} & \multirow{2}{*}{$\begin{array}{l}D \\
4\end{array}$} & \multirow{2}{*}{$\begin{array}{c}\text { DS } \\
5\end{array}$} \\
\hline & & & & & & & \\
\hline \multirow[t]{4}{*}{ Management Companies: } & Small & [ 21 ] & 0.0 & 14.3 & 42.9 & 28.6 & 14.3 \\
\hline & Medium & [4] & 0.0 & 0.0 & 50.0 & 50.0 & 0.0 \\
\hline & Large & [ 7 ] & 14.3 & 0.0 & 28.6 & 42.8 & 14.3 \\
\hline & Total & {$[32$ ] } & 3.1 & 9.4 & 40.6 & 34.4 & 12.5 \\
\hline Banks: & {$[15]$} & 6.7 & 26.6 & 46.7 & 0.0 & 20.0 & \\
\hline
\end{tabular}

AS 1= Agree Strongly; A 2= Agree; 3= No Clear Opinion; D 4= Disagree; DS 5= Disagree Strongly 
This question was asked to establish more clearly whether enhanced reputation had resulted in a competitive benefit to Mauritius. After all, if regulation was strengthened to make the financial system sounder and safer, and to protect the interests of offshore clients better, it should have: (a) incentivised existing clients to do more business in Mauritius; and (b) prompted more new clients to use the services of Mauritius as an IFC. Yet, the response to this question from both MCs and banks was strangely reserved and ambiguous. Most felt that financial regulation had been strengthened, and Mauritius' reputation enhanced, by the new AML/CFT regime. Whether they presumed this was the case axiomatically (i.e. if regulation is strengthened, reputation must automatically be enhanced), or whether they actually discerned this from surveying their clients, is unknown. However, oddly enough, a sizeable 41 per cent of MCs and 47 per cent of banks had 'no opinion' on whether the competitiveness of Mauritius had been increased as a result, while 47 per cent of MCs and 20 per cent of banks disagreed with this view. That left only a small minority (12.5 per cent) of MCs and a more substantial minority (a third) of banks actually agreeing that competitiveness had been increased.

When this view was tested at the seminar, the above finding was altered resoundingly. During the seminar respondents stepped off the fence and expressed a virtually unanimous view that Mauritius' competitiveness had definitely been diminished as a consequence of the new AML/CFT regime. Most discussants who spoke cited anecdotal evidence of losing extant clients (a real loss) as well as losing potential business they thought they 'had in the bag' (an opportunity cost). They were adamant that this was because of a view among offshore clients that regulation in Mauritius had become so demanding, bureaucratic and mindless, that they would rather shift their business elsewhere; not just to new jurisdictions like Dubai, but also to supposedly more stringent jurisdictions like Singapore and London, which clients felt were actually more flexible and reasonable in their disclosure information demands than regulators in Mauritius.

Thus, respondents who participated in the seminar made it abundantly clear that, while the reputation of Mauritius as an IFC may in theory have been enhanced, that did little or nothing in practice in terms of enhancing its competitiveness from a business viewpoint. Indeed, it may even have had the opposite effect: the IFS industry in Mauritius felt that its image and prospects had been damaged rather than assisted by the way in which AML/CFT regulation had actually been introduced and implemented.

With this important issue articulated and put to rest, the rest of this section focuses on respondents' views about the specific benefits derived by their firms (rather than by Mauritius generally) along a variety of parameters and dimensions. 
What has been the impact of new KYC/DD compliance requirements on your firm's overall business; i.e. by what percentage has it increased or decreased?

\begin{tabular}{|c|c|c|c|c|c|c|c|c|c|}
\hline \multicolumn{3}{|l|}{ Responses from } & \multirow{2}{*}{$\begin{array}{l}\text { NS } \\
4.8\end{array}$} & \multicolumn{3}{|c|}{ Business decreased by: } & \multicolumn{3}{|c|}{$\begin{array}{c}\text { Business increased by: } \\
0-15 \%>15-30 \%>30 \%\end{array}$} \\
\hline Management & Small & [ 21 ] & & 19.0 & 4.8 & 19.0 & 28.6 & 9.5 & 14.3 \\
\hline \multirow[t]{3}{*}{ companies } & Medium & [ 4 ] & 0.0 & 55.0 & 0.0 & 0.0 & 25.0 & 25.0 & 0.0 \\
\hline & Large & [ 7 ] & 0.0 & 14.3 & 0.0 & 0.0 & 46.7 & 33.3 & 6.7 \\
\hline & Total & [ 32 ] & 3.1 & 21.9 & 3.1 & 12.5 & 25.0 & 15.6 & 18.8 \\
\hline Banks: & [ 15$]$ & 0.0 & 13.3 & 0.0 & 0.0 & 46.7 & 33.3 & 6.7 & \\
\hline
\end{tabular}

NS: Not Specified

As is evident from the table above, the revenues of a majority of respondents, MCs (over 59\%) and banks (87 per cent) saw an overall increase in their turnover between 2002 and 2005. Most of these witnessed an increase of 0-15 per cent, which is to be expected as normal or average under typical business circumstances. Over 40 per cent of MCs (and over 45 per cent of small and medium MCs) saw a decline in their revenues. Most of these saw a decrease in the $0-15$ per cent range, although four small MCs suffered a decline of more than 30 per cent. The question asked specifically whether the increase/decrease was due to the impact of new KYC/DD compliance requirements. However, private discussions with respondents during the seminar revealed that the responses reflected actual increases/decreases in revenues without specific attribution to increased KYC/DD requirements when revenues increased, yet definitely ascribing the decline to KYC/DD demands when revenues decreased. That asymmetry suggests that the results above need to be interpreted with caution. The pattern of responses reflects what has happened to MCs and banks in terms of their business volume (gross revenues) over the last four years. However, it invalidates the purpose of the question with the responses not being properly attributable to any particular reason. Another problem with the question is that it did not specify whether the decline was in annual (i.e. annually for each of the four years) or aggregate terms (i.e. overall increase/decrease over the four year period as a whole). The result was a mixed response. Some respondents indicated annual performance, while others answered for the aggregate over the period.

The overall picture that emerges is therefore confusing in that the qualitative responses do not fully reflect the several opinions expressed about lost business. However, the fact that over 40 per cent of small and medium MCs saw their revenues fall does partially support that picture and is disconcerting. The fact that two (out of 15) banks saw revenues fall by $0-15$ per cent contrasts with the picture for MCs. These banks did not attribute KYC/DD specifically as being responsible for their revenue declines. The general picture that emerges is that the new AML/CFT regime did not result in an overall revenue loss for the IFS industry. Instead, at least three (out of the seven reporting) large MCs and the overwhelming majority of banks (13 out of 15 responding) saw 
increased revenues ( 40 per cent of them by more than 15 per cent), while many small and medium MCs lost revenues in the post-2002 regulatory environment.

That finding has implications for increasing concentration of market power among MCs in the IFS industry (a fact borne out also by the large market share - 60 per cent of large MCs and their even larger share - 75 per cent - of the industry's net profits) which should cause policy-makers and regulators some concern. If additional regulation has the net effect of increasing the concentration of a larger market share among fewer companies then it is probably discouraging competition of the kind needed to have a thriving IFS industry by making the costs of regulation unbearable for small firms.

What has been the impact of new KYC/DD compliance requirements on your firm's total revenue from IFS activity?

\begin{tabular}{|c|c|c|c|c|c|c|c|}
\hline \multicolumn{3}{|c|}{ Responses from } & \multirow{2}{*}{$\begin{array}{c}\text { Nil } \\
1\end{array}$} & \multicolumn{2}{|c|}{ Low Moderate } & \multirow{2}{*}{$\begin{array}{c}\text { High } \\
4\end{array}$} & \multirow{2}{*}{$\begin{array}{c}N S \\
5\end{array}$} \\
\hline & & & & 2 & 3 & & \\
\hline \multirow{4}{*}{$\begin{array}{l}\text { Management: } \\
\text { companies }\end{array}$} & Small & {$[21]$} & 23.8 & 38.1 & 33.3 & 0.0 & 4.8 \\
\hline & Medium & [ 4 ] & 25.0 & 50.0 & 25.0 & 0.0 & 0.0 \\
\hline & Large & [ 7 ] & 0.0 & 28.6 & 71.4 & 14.3 & 0.0 \\
\hline & Total & [ 32 ] & 9.3 & 21.9 & 40.6 & 15.6 & 9.3 \\
\hline \multicolumn{2}{|l|}{ Banks: } & [ 15 ] & 20.0 & 13.4 & 53.2 & 13.4 & 0.0 \\
\hline
\end{tabular}

Although this question seeks almost the same information about revenues, but without specifying percentages, it elicits a supportive pattern of responses thus confirming by a cross-check the validity of responses on how revenues have been affected by the new AML/CFT regime. Nearly 41 per cent of MCs and over 53 per cent of the banks saw the impact on revenues as being moderate (which compares with the 41 per cent of MCs that saw increases in revenues of $0-30$ per cent and 47 per cent of banks that saw an increase of $0-15$ per cent; obviously the MCs and banks interpreted the word 'moderate' differently).

By the same token, nearly 16 per cent of MCs saw the (negative) revenue impact of new $\mathrm{KYC} / \mathrm{DD}$ requirements as being high (compared to the 16 per cent whose revenues declined by over 15 per cent) while 13.3 per cent of banks saw the revenue impact as high. This again corresponds exactly with the 13.3 per cent of banks that registered a revenue decline in answering the previous question. This pattern of responses confirms the finding that, while MCs and banks were quick to link additional KYC/ $\mathrm{DD}$ requirements with declines in revenue, they were less ready to associate increases in revenue to the same $\mathrm{KYC} / \mathrm{DD}$ requirements, as that would have seemed counterintuitive. 
What has been the impact of new KYC/DD compliance requirements on your firm's incremental profits from IFS activity?

\begin{tabular}{|c|c|c|c|c|c|c|c|}
\hline \multicolumn{3}{|c|}{ Responses from } & \multirow{2}{*}{$\begin{array}{c}\text { Nil } \\
1\end{array}$} & \multicolumn{2}{|c|}{ Low Moderate } & \multirow{2}{*}{$\begin{array}{c}\text { High } \\
4\end{array}$} & \multirow{2}{*}{$\begin{array}{c}\text { NS } \\
5\end{array}$} \\
\hline & & & & 2 & 3 & & \\
\hline \multirow{4}{*}{$\begin{array}{l}\text { Management: } \\
\text { companies }\end{array}$} & Small & [ 21 ] & 33.3 & 28.6 & 33.3 & 0.0 & 4.8 \\
\hline & Medium & [ 4 ] & 75.0 & 0.0 & 25.0 & 0.0 & 0.0 \\
\hline & Large & [ 7 ] & 14.3 & 57.1 & 28.6 & 0.0 & 0.0 \\
\hline & Total & [ 32 ] & 34.3 & 31.3 & 31.3 & 0.0 & 3.1 \\
\hline \multicolumn{2}{|l|}{ Banks: } & [ 13] & 7.7 & 69.2 & 23.1 & 0.0 & 0.0 \\
\hline
\end{tabular}

Contrary to the picture presented on revenues, the situation with regard to MC and bank profits is more subdued. No MC or bank recorded the impact on profits as being high. A significant minority ( 31 per cent of MCs and 23 per cent of banks) recorded it as moderate. The majority of MCs (66 per cent) and banks ( 77 per cent) felt that the impact on profits was nil or low. Profits-wise, MCs have been having a poor time. Annual profits averaged US $\$ 5.5$ million for the MC industry in 2001-03. However, they fell to US\$1.6 million in 2004 and are estimated to have recovered to just under US\$4 million in 2005.

The profit performance of MCs is surprising. Turnover had not declined in 20012005, although it levelled off in 2002-2003. However, expenses (mainly the costs of regulation) took a quantum leap in 2004 and have stayed on a higher plateau since. Discussions with a number of MCs suggest that the loss of profitability of individual firms reflects the loss of competitiveness of Mauritius as an IFC; nonetheless, differences in the profit performance of small and large MCs also suggest that economies of scale are a factor in determining competitiveness at the level of the individual firm.

What has been the impact of your firm's response to the new AML/CFT compliance regime on increased staff efficiency and productivity?

\begin{tabular}{|c|c|c|c|c|c|c|c|}
\hline \multicolumn{3}{|c|}{ Responses from } & \multirow{2}{*}{$\begin{array}{c}\text { Nil } \\
1\end{array}$} & \multicolumn{2}{|c|}{$\begin{array}{l}\text { Low Moderate } \\
(\%)\end{array}$} & \multirow{2}{*}{$\begin{array}{c}\text { High } \\
4\end{array}$} & \multirow{2}{*}{$\begin{array}{c}N S \\
5\end{array}$} \\
\hline & & & & 2 & 3 & & \\
\hline \multirow{4}{*}{$\begin{array}{l}\text { Management: } \\
\text { companies }\end{array}$} & Small & [ 21 ] & 19.0 & 28.6 & 33.3 & 14.3 & 4.8 \\
\hline & Medium & [ 4] & 50.0 & 25.0 & 25.0 & 0.0 & 0.0 \\
\hline & Large & [ 7 ] & 14.3 & 28.6 & 42.9 & 14.3 & 0.0 \\
\hline & Total & [ 32] & 21.9 & 28.1 & 34.4 & 12.5 & 3.1 \\
\hline \multicolumn{2}{|l|}{ Banks: } & [ 13 ] & 0.0 & 53.8 & 46.2 & 0.0 & 0.0 \\
\hline
\end{tabular}

Responses on this question were evenly divided. Half of the MCs and just over half the banks (54 per cent) responding indicated that the impact on staff efficiency/productivity had been nil/low while just under a half in each case (i.e. MCs and banks) reported 
that it had been moderate/high, although those MCs reporting 'high' were in a minority and represented just one large firm along with three small firms. Clearly the industry has not attempted to cope with increased compliance costs by squeezing more efficiency/productivity out of staff. MCs and banks have just increased staff numbers. Perhaps staff efficiency/productivity were already high, compliance machinery and systems were close to perfect, and higher efficiency could not be squeezed out through greater reliance on better IT systems. Whatever the reason, it is clear that in Mauritius the introduction of a new AML/CFT regime did not have any benefit by way of improved systemic efficiency in the IFS industry's compliance-response.

What has been the impact of your firm's response to the new AML/CFT compliance regime on increased client base and client source diversification?

\begin{tabular}{|c|c|c|c|c|c|c|c|}
\hline \multicolumn{3}{|c|}{ Responses from } & \multirow{2}{*}{$\begin{array}{c}\text { Nil } \\
1\end{array}$} & \multicolumn{2}{|c|}{ Low $_{(\%)}$ Moderate } & \multirow{2}{*}{$\begin{array}{c}\text { High } \\
4\end{array}$} & \multirow{2}{*}{$\begin{array}{c}N S \\
5\end{array}$} \\
\hline & & & & 2 & 3 & & \\
\hline \multirow{4}{*}{$\begin{array}{l}\text { Management: } \\
\text { companies }\end{array}$} & Small & [ 21] & 28.6 & 38.1 & 23.8 & 4.8 & 4.8 \\
\hline & Medium & [4] & 50.0 & 50.0 & 0.0 & 0.0 & 0.0 \\
\hline & Large & [ 7 ] & 14.3 & 42.9 & 28.6 & 14.3 & 0.0 \\
\hline & Total & [ 32 ] & 28.1 & 40.6 & 21.9 & 3.1 & 3.1 \\
\hline \multicolumn{2}{|l|}{ Banks: } & [ 13 ] & 15.4 & 61.6 & 15.4 & 7.7 & 0.0 \\
\hline
\end{tabular}

At present, measured in terms of inward investments or sources of funds (a better indicator than the origin of supposedly beneficial owners, since these are categorised by the nationality of the shell corporations and trusts set up to own offshore assets rather than by the nationality of the real eventual beneficial owner), almost threequarters of Mauritian IFS business is heavily dependent on a continuing flow of inward investments by clients from India ( 54 per cent) and Indonesia (18 per cent). Clients of Chinese origin (from China, Singapore and Hong Kong collectively) account for another 13 per cent. African clients account for 5 per cent (of which twothirds are from South Africa), and clients from all other countries/regions account for a collective 10 per cent. These clients have invested mainly in the (equity and debt) of companies and trusts of in countries such as the USA (27 per cent), Singapore and Hong Kong (24 per cent), other OFCs (20 per cent), the UK (9 per cent) and other countries (including Indonesia, India etc.) - 17 per cent. Thus the Mauritian IFS industry (MCs and banks) is exposed to a high concentration risk.

A key observation made by the First Deputy Governor of the BoM at the seminar was that Mauritian MCs and banks had not done enough to diversify either their geographic market base or to widen and deepen the range of products/services they offered. They were still too dependent for their business on the Indian and Indonesian tax treaties. Conditions in both countries could change easily; e.g. India might soon go for full convertibility of the Indian rupee (Rs) and drop all the NRI investment preferences it presently provides. This might result in a sudden loss of business as a 
consequence. There is much substantive merit in this observation, which the industry would do well to take up as a strategic challenge and heed.

If the new AML/CFT regime has indeed enhanced the reputation of Mauritius as a well-regulated IFC, it is not implausible to suggest that, as a result, Mauritian MCs and banks (with marketing effort in other countries and regions) should attract a larger number of clients from a wider number of places. This question was asked to test that assumption.

A significant majority of respondents (69 per cent of MCs and 77 per cent of banks) felt that the new AML/CFT regime had done little or nothing to assist either client type or source diversification. In other words, the supposed positive reputation effect had not translated itself into a tangible benefit by way of either increased or more diversified business. A small minority of MCs (22 per cent) and banks (15 per cent) felt that the new regime had resulted in a moderate impact, while only one large $\mathrm{MC}$ and one bank felt that the impact had been high. How much this outcome has to do with the inherent conservatism and complacency of MCs in the Mauritian IFS industry, and how much it has to do with the effects of the AML/CFT regime, is difficult to discern or attribute. However, it is an issue worthy of further exploration by the IFS industry and government. An answer to that question is crucial in determining the future viability, growth and direction of Mauritius as an IFC.

What has been the impact of the new AML/CFT compliance regime on increased access to foreign markets?

\begin{tabular}{|c|c|c|c|c|c|c|c|}
\hline \multicolumn{3}{|c|}{ Responses from } & \multirow{2}{*}{$\begin{array}{c}\text { Nil } \\
1\end{array}$} & \multicolumn{2}{|c|}{ Low Moderate } & \multirow{2}{*}{$\begin{array}{c}\text { High } \\
4\end{array}$} & \multirow{2}{*}{$\begin{array}{c}\text { NS } \\
5\end{array}$} \\
\hline & & & & 2 & 3 & & \\
\hline \multicolumn{2}{|c|}{ Management: Small [ 21 ] } & 19.0 & 52.4 & 14.3 & 9.5 & 4.8 & \\
\hline \multirow[t]{3}{*}{ companies } & Medium & [4] & 75.0 & 0.0 & 25.0 & 0.0 & 0.0 \\
\hline & Large & {$[7]$} & 14.3 & 57.1 & 14.3 & 14.3 & 0.0 \\
\hline & Total & [ 32 ] & 25.0 & 46.9 & 15.6 & 9.3 & 3.1 \\
\hline Banks: & & [ 13 ] & 7.7 & 46.2 & 38.4 & 7.7 & 0.0 \\
\hline
\end{tabular}

As an extension of the previous question, the response rate is similar though not identical. Nearly 72 per cent of MCs and 54 per cent of banks indicated that the new AML/CFT regime had either no impact or a low impact on the geographic diversification of clientele. Again, however, it is debatable whether it was the additional burden of regulation, or the general complacency of the industry, that is responsible for that outcome. More banks (38 per cent) than MCs (16 per cent) felt there was a moderate impact while only 9 per cent of MCs and 8 per cent of banks though the impact on increased access to foreign markets was high. Again, the responses to this question underlined the fact that even if enhanced AML/CFT regulation had improved the reputation of Mauritius, it had not done much in attracting a wider geographical client base. 
What has been the impact of the new AML/CFT compliance regime on increased product and service diversification by your firm?

\begin{tabular}{|c|c|c|c|c|c|c|c|}
\hline \multicolumn{3}{|c|}{ Responses from } & \multirow{2}{*}{$\begin{array}{c}\text { Nil } \\
1\end{array}$} & \multicolumn{2}{|c|}{$\operatorname{Lw}_{(\%)}$ Moderate } & \multirow{2}{*}{$\begin{array}{c}\text { High } \\
4\end{array}$} & \multirow{2}{*}{$\begin{array}{c}N S \\
5\end{array}$} \\
\hline & & & & 2 & 3 & & \\
\hline \multirow{4}{*}{$\begin{array}{l}\text { Management: } \\
\text { companies }\end{array}$} & Small & [ 21 ] & 33.3 & 38.1 & 19.0 & 4.8 & 4.8 \\
\hline & Medium & [4] & 75.0 & 0.0 & 25.0 & 0.0 & 0.0 \\
\hline & Large & [ 7 ] & 28.6 & 42.9 & 28.6 & 0.0 & 0.0 \\
\hline & Total & [ 32 ] & 37.5 & 34.4 & 31.9 & 3.1 & 3.1 \\
\hline \multicolumn{2}{|l|}{ Banks: } & [ 13$]$ & 23.1 & 46.2 & 23.1 & 7.7 & 0.0 \\
\hline
\end{tabular}

The table above provides support for the criticism that the IFS industry is complacent. In the face of the increased challenge posed by the toughening of the AML/CFT regime, one might have expected the IFS industry to exert active efforts to both diversify its client base and diversify its range of products and services. The previous two tables showed that the industry had failed to diversify geographically. This table supports the view that the IFS industry has failed to diversify functionally as well. Nearly 72 per cent of MCs and over 69 per cent of banks reported that the functional diversification impact of enhanced AML/CFT regulation was either nil or low. Only 35 per cent of MCs and 31 per cent of banks reported a moderate or high impact on product/ service diversification.

One explanation might be that tougher AML/CFT regulation has dampened rather than increased the ability of MCs to look beyond their extant geographical client base and offer more products and services to attract new business from existing as well as potential clients. A second reason might be that the additional resources expended by MCs on strengthening compliance regimes have diverted resources away from strategic marketing and business development pursuits. There is some support for this explanation from responses to the question on whether the new regime had diverted attention from more important business priorities. However, the response leaves unanswered the question of whether the IFS industry is picking up the gauntlet and addressing the challenge of survival and growth in the face of enhanced regulation, with its supposedly concomitant reputation-enhancing effects.

What has the impact of the new AML/CFT regime been on increasing the competitiveness of Mauritius as an IFC?

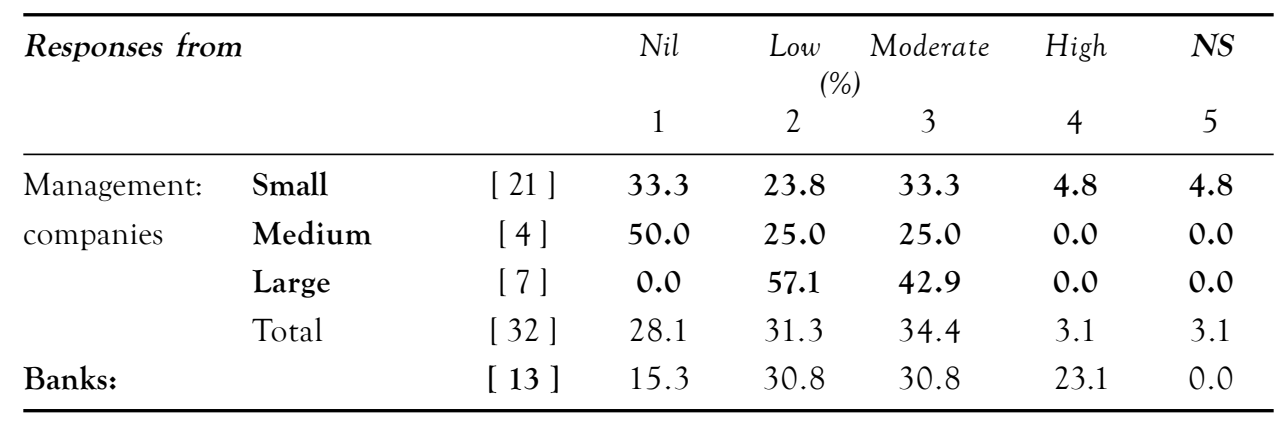


This again was a test question aimed to cross-check a previously elicited opinions, but in a slightly different context. However, the pattern of responses this time was different from previous responses to almost the same question. Previously, the largest proportion of MCs and banks (41 per cent and 47 per cent respectively) had expressed no opinion on whether the competitiveness of Mauritius had increased or not as a result of the new AML/CFT regime; almost 47 per cent of MCs and 21 per cent of banks thought that Mauritius had not become more competitive while 12 per cent of MCs and 32 per cent of banks thought it had. This time, however, 59 per cent of MCs and 46 per cent of banks thought that the new AML/CFT regime had little or no impact on increasing the competitiveness of Mauritius, while 38 per cent of MCs and 54 per cent of banks thought that the impact on increasing competitiveness was moderate or high.

This inconsistency is difficult to explain other than as a possible misunderstanding of the statement on the part of respondents (i.e. misinterpreting 'increased competitiveness' for 'decreased competitiveness'). The inconsistency might also be explained if the respondents who had previously expressed 'no opinion' (in private discussions some indicated that they had taken a neutral position in responding to the questionnaires in order to avert any prospect of regulatory retaliation) were evenly divided between those that thought competitiveness had increased and those who felt it had not. Equally difficult to explain was the inconsistency between these findings and the almost unanimous sense expressed by discussants at the seminar that Mauritius had definitely become less competitive as an IFC as a consequence of the new AML/CFT regime.

What has the impact of the new AML/CFT regime been on increasing the competitiveness of your firm in the Mauritian IFC sector?

\begin{tabular}{|c|c|c|c|c|c|c|c|}
\hline \multicolumn{3}{|c|}{ Responses from } & $\begin{array}{c}\text { Nil } \\
1\end{array}$ & Low & Moderate & $\begin{array}{c}\text { High } \\
4\end{array}$ & $\begin{array}{c}\text { NS } \\
5\end{array}$ \\
\hline Management: & Small & {$[21]$} & 28.6 & 42.9 & 23.8 & 0.0 & 4.8 \\
\hline \multirow[t]{3}{*}{ Companies } & Medium & [ 4 ] & 25.0 & 50.0 & 25.0 & 0.0 & 0.0 \\
\hline & Large & [ 7 ] & 0.0 & 28.6 & 42.9 & 28.6 & 0.0 \\
\hline & Total & [ 32 ] & 28.1 & 31.3 & 34.4 & 3.1 & 3.1 \\
\hline Banks: & & [ 13 ] & 23.1 & 30.8 & 30.8 & 15.3 & 0.0 \\
\hline
\end{tabular}

In responding to this question, over 59 per cent of all MCs indicated low or no impact of the new AML/CFT regime on increasing the competitiveness of their firm within the IFS industry. However, the difference between small and large MCs was sharp and reflected their profitability numbers. While nearly 72 per cent of small and mediumsized MCs felt that the impact on their increased competitiveness had been nil/low, 72 per cent of the large MCs felt that the impact on their competitiveness had been moderate/high. Clearly, this finding confirms the generally held view that increased regulation has strengthened the position of large firms in the Mauritian MC space. That may lead to further consolidation as economies of scale dominate. Smaller firms 
will become less profitable and less able to afford the recurrent costs of a much more demanding regulatory/compliance regime. That may mean less competition in the industry, with a 'weeding out' of small firms that cannot afford to remain in the business. Among banks, opinion was more evenly divided; 54 per cent thought that their competitiveness had not increased significantly while 46 per cent thought it had.

Improved knowledge: The next three questions were aimed at determining whether a change in the regulatory regime with higher compliance demands had any impact on firms deriving potential benefits from improving their technical capacity, knowledge base and risk management capabilities. Thus, these three questions revolve around the same premise - i.e. to what extent have firms in the IFS industry used the increased knowledge they have acquired to respond to more demanding compliance requirements to their advantage? However, the questions yield different patterns of answers in each case. The responses suggest that such benefits, to the extent that they were perceived to have accrued, were probably marginal.

What impact has the new AML/CFT regime had on improving the technological capacity of your firm?

\begin{tabular}{|c|c|c|c|c|c|c|c|}
\hline \multicolumn{3}{|c|}{ Responses from } & \multirow{2}{*}{$\begin{array}{c}\text { Nil } \\
1\end{array}$} & \multicolumn{2}{|c|}{ Low $_{(\%)}$ Moderate } & \multirow{2}{*}{$\begin{array}{c}\text { High } \\
4\end{array}$} & \multirow{2}{*}{$\begin{array}{c}N S \\
5\end{array}$} \\
\hline & & & & 2 & 3 & & \\
\hline \multirow{4}{*}{$\begin{array}{l}\text { Management: } \\
\text { companies }\end{array}$} & Small & [ 21] & 9.5 & 28.6 & 52.4 & 0.0 & 4.8 \\
\hline & Medium & [ 4 ] & 50.0 & 25.0 & 25.0 & 0.0 & 0.0 \\
\hline & Large & {$[7]$} & 0.0 & 42.9 & 57.1 & 0.0 & 0.0 \\
\hline & Total & [ 32 ] & 12.5 & 31.3 & 50.0 & 0.0 & 6.3 \\
\hline \multicolumn{2}{|l|}{ Banks: } & [ 13 ] & 7.7 & 38.5 & 46.2 & 7.7 & 0.0 \\
\hline
\end{tabular}

What impact has the new AML/CFT regime had on improving the knowledge base of your firm?

\begin{tabular}{|c|c|c|c|c|c|c|c|}
\hline \multicolumn{3}{|c|}{ Responses from } & \multirow{2}{*}{$\begin{array}{c}\text { Nil } \\
1\end{array}$} & \multirow{2}{*}{$\begin{array}{l}\text { Low } \\
2\end{array}$} & \multirow{2}{*}{$\begin{array}{c}\text { Moderate } \\
3\end{array}$} & \multirow{2}{*}{$\begin{array}{c}\text { High } \\
4\end{array}$} & \multirow{2}{*}{$\begin{array}{c}\text { NS } \\
5\end{array}$} \\
\hline & & & & & & & \\
\hline Management: & Small & [ 21$]$ & 4.8 & 28.6 & 42.9 & 19.0 & 4.8 \\
\hline \multirow[t]{3}{*}{ companies } & Medium & [ 4 ] & 25.0 & 50.0 & 0.0 & 25.0 & 0.0 \\
\hline & Large & [ 7 ] & 0.0 & 42.9 & 42.9 & 14.3 & 0.0 \\
\hline & Total & [ 32 ] & 6.3 & 34.4 & 37.5 & 18.7 & 3.1 \\
\hline Banks: & & [ 13 ] & 0.0 & 30.8 & 61.5 & 7.7 & 0.0 \\
\hline
\end{tabular}


What impact has the new AML/CFT regime had on increasing profitability from improved risk management in your firm?

\begin{tabular}{|c|c|c|c|c|c|c|c|}
\hline \multicolumn{3}{|c|}{ Responses from } & \multirow{2}{*}{$\begin{array}{c}\text { Nil } \\
1\end{array}$} & \multicolumn{2}{|c|}{ Low $_{(\%)}$ Moderate } & \multirow{2}{*}{$\begin{array}{c}\text { High } \\
4\end{array}$} & \multirow{2}{*}{$\begin{array}{c}\text { NS } \\
5\end{array}$} \\
\hline & & & & 2 & 3 & & \\
\hline \multirow{4}{*}{$\begin{array}{l}\text { Management: } \\
\text { companies }\end{array}$} & Small & [ 21] & 23.8 & 23.8 & 38.1 & 9.6 & 4.8 \\
\hline & Medium & [ 4 ] & 50.0 & 25.0 & 25.0 & 0.0 & 0.0 \\
\hline & Large & [ 7 ] & 14.3 & 42.9 & 42.9 & 0.0 & 0.0 \\
\hline & Total & [ 32 ] & 28.1 & 28.1 & 37.5 & 6.2 & 3.1 \\
\hline \multicolumn{2}{|l|}{ Banks: } & [ 13 ] & 0.0 & 61.5 & 30.8 & 7.7 & 0.0 \\
\hline
\end{tabular}

Where almost all (except four MCs and one bank) respondents agree is that there has been some positive impact of the new AML/CFT regime in improving technological capacity and knowledge base. A significant minority of MCs (31 per cent in the case of technological capacity, 34 per cent in the case of improved knowledge base and 28 per cent in the case of better risk management) thought that the beneficial impact was low. Meanwhile, 28 per cent of MCs thought that there was no impact at all as far as increasing profitability from improved risk management was concerned. Half of all MCs thought that the impact on improving their technological capacity was moderate, while 56 per cent thought that the impact on improving their knowledge base was moderate/high. When it came to risk management, however, fewer than 44 per cent of MCs thought that its positive impact on their profitability was moderate/high.

The pattern for banks was different and more evenly divided. Over 46 per cent of banks thought that the impact on improved technological capacity was nil/low while 54 per cent thought it was moderate/high. When it came to an improved knowledge base, however, over 69 per cent of banks thought that the impact was moderate/high, but only 39 per cent thought they had derived any benefit in terms of profitability from better risk management

Though it is difficult to come up with a definitive overall conclusion from the pattern of responses for these three 'knowledge-based' questions, the general sense that can be derived is that the tangible benefits of improved knowledge were generally perceived to be marginal and intangible - i.e. not translated into greater efficiency, lower costs, higher revenues or higher profitability. However, as indicated before, the absence of a translation effect from intangible to tangible benefit does not concern the AML/CFT regime alone. It also concerns the intrinsic ability of firms and banks to undertake the effort to enable such translation. 


\subsection{Overall conclusions from the analysis of survey findings for Mauritius}

\section{Drawing firm conclusions about costs and benefits of the enhanced AML/ CFT regime}

What conclusions can be drawn from the analysis of survey responses outlined in the previous two sections when, on many issues, the responses are ambiguous or opinions evenly divided? To the extent possible, the substance of discussions at the seminar has been relied upon to make clearer issues on which survey responses were confused. Clearly, definitive conclusions, extruded from the survey and seminar, are vulnerable to argument about what was said, what was meant, how it should be interpreted and whether a counter-conclusion might not be equally valid. Allowing for that uncertainty, and leaving itself open to amendment, this chapter takes the risk of drawing out some qualified conclusions (for which the lead consultant takes full responsibility) from what has been learnt about: (a) the manner in which enhanced AML/CFT regulation was introduced and implemented in Mauritius and the reasoning of regulators to justify doing what they did; and (b) its overall impact on the IFS industry by way of costs and benefits.

Recognising that many differences of opinion exist between regulators and the IFS industry, as well as within the IFS industry itself (i.e. between MCs and banks, and between large and small or medium MCs) what are the areas in which the survey findings reflected some degree of broad agreement across the board? Simply put, these areas include the following:

- Enhanced AML/CFT legislation and regulation had to be introduced in Mauritius, and the IFS industry was obliged to comply with it. However, the pressures for such enhancement did not emanate from within. They were exerted by external interlocutors (i.e. the Financial Action Task Force [FATF] and international financial institutions) who demanded (excessive?) enhancements regardless of the quality of the extant regulatory regime.

- Such pressures had to be accommodated by Mauritian policy-makers and regulators in order to avoid the threat of being blacklisted by the FATF and risking the IFS industry being put out of business. [That presumes that blacklisting would have put the IFS industry out of business. However, would it? Of course in the US, the Patriot Act cuts off blacklisted jurisdictions and their foreign banks from doing business in America, which makes it difficult for any bank that transacts in US dollars to operate.]

- Enhanced AML/CFT regulation has bolstered the reputation of Mauritius as an IFC. It is now regarded as a well-regulated financial jurisdiction that has the good housekeeping seal of approval of the IFIs. However, the conclusion about 'bolstered reputation' is based on axiomatic presumption rather than definitive objective knowledge acquired by surveying offshore clientele. Whether Mauritius' repu- 
tation is regarded by offshore clients as being better than it was before, or better than that of other IFCs/OFCs at the time of writing, is unknown.

- The bolstering of its reputation as a well-regulated financial jurisdiction has not resulted in any discernible tangible benefits accruing to Mauritius by way of enhanced competitiveness resulting in additional business. On the other hand, enhanced AML/CFT legislation has not led to a loss of gross turnover (revenue) on the part of the IFS industry, despite anecdotal evidence of lost business.

- While the reputational benefit of the enhanced AML/CFT regime has not yielded tangible returns, it has resulted in definite and large costs (direct, indirect and opportunity) that appear to have affected the profitability of the management companies, but not that of the offshore banks.

The above are the principal areas of agreement across all the parties concerned. The remaining conclusions of the study, outlined below, are contentious, reflecting in part the views of an oft-quoted, anonymous government bureaucrat who opined that: 'where he stood on an issue depended on where he was sitting at the time'. Taking this into account, the other conclusions the study arrives at, and the questions that they raise, include the following:

- Acknowledging that Mauritius was under intense external pressure to strengthen its AML/CFT regulatory and compliance regime in accord with new international standards set by the FATF and monitored by the IFIs, a conclusion of the study is that Mauritian policy-makers and regulators were perhaps too quick and over-anxious in making commitments to OECD and FATF. They did not take fully into account the impact of these commitments on the IFS industry. Nor were these commitments based on any prior consultation with the IFS industry aimed at arriving at a common position.

- Mauritian policy-makers and regulators simply presumed that they knew what was in the best interests of Mauritius and of the IFS industry. By attempting to be 'frontrunners' in meeting new international standards and over-pleasing their interlocutors, Mauritian policy-makers gambled on gaining a competitive advantage for the IFS industry, which has not materialised. In fact, the industry (i.e. MCs) believes that it has become uncompetitive as a result. The experience may even have shown that Mauritius will succumb much too easily to international pressure, even when such pressure might militate against its national interests.

- From quantitative submissions made by regulatory agencies, and a large sample of MCs and banks from which industry totals have been extrapolated, the incremental costs of introducing/implementing the new AML/CFT regime are estimated to have been just over US\$40 million over the four years 2002-05. In general, both regulators and the IFS industry have responded to new challenges by adding staff resources rather than by investments in IT systems. The proportion of new investment in IT systems to meet the additional demands of AML/CFT regulation has been lower than in other jurisdictions (although there is some evidence that it may 
have been under-reported). In the case of foreign bank subsidiaries/branches, it is a cost that appears to have been absorbed by head offices rather than at the local level.

- Inconsistencies in the qualitative and quantitative data provided, gaps in detailed breakdowns and estimates provided by regulators in apportioning part of their total regulatory/supervisory costs to the AML/CFT regime using arbitrary percentages, caused the lead consultant to believe that the total incremental cost may be understated by $25-30$ per cent. The actual costs may therefore be around US $\$ 50$ million rather than US $\$ 40$ million, although it is the latter figure that is used here for analytical purposes.

- This figure (US\$40 million) does not include the costs of implementing the new $\mathrm{AML} / \mathrm{CFT}$ regime, and its associated KYC/DD requirements, for the insurance and securities industries. Using estimates provided by these other groups during the seminar, the total incremental cost of applying the new AML/CFT regime to all financial services (domestic and offshore) in Mauritius may be closer to US\$60 million over the four years. In proportional terms that would be equivalent to the UK or France incurring a cost of US $\$ 30$ billion, the US incurring a cost of US $\$ 150$ billion, India incurring a cost of US $\$ 8$ billion and Singapore incurring a cost of US $\$ 1.5$ billion for the same purpose over the same period.

- Of the total incremental cost incurred by regulators and the IFS industry, about 12 per cent has been borne by the government and regulators, 20 per cent by banks and the remaining 68 per cent by management companies. That asymmetry is particularly onerous. The cost to the public sector (less than US $\$ 5$ million) has been absorbed as a small fraction of the national budget, while offshore banks have been 15 times more profitable than MCs over the four-year period. Aggregate aftertax profits for offshore banks in 2002-05 were US\$262 million (compared to incremental costs of around US $\$ 8$ million) while those for MCs were just over US $\$ 17$ million (compared to industry-wide incremental costs of over US\$27 million). The brunt of the additional cost burden has thus been borne by those institutions least capable of bearing it. This is particularly true in the case of the 66 small MCs, which together account for less than 25 per cent of the IFS market and less than 20 per cent of the MC industry's profits.

- A possible consequence of the above may be a trend toward consolidation and concentration in the structure of the MC industry. Whether that would, in an overall sense, be a good thing (because small weak MCs vulnerable to risk would be weeded out or would merge to achieve better economies of scale) or a bad thing (because it would lead to greater market power on the part of a few large firms which already dominate a large proportion of market share) needs to be looked into further.

- The incremental costs of the new AML/CFT regime are regarded by regulators as being low and acceptable as a cost of doing business. That view is supported by half the banks involved in offshore banking. However, it is opposed by the MC 
industry, which has borne most of the cost. Judging by comparisons with other jurisdictions of various sizes (see above) the incremental costs of adopting the new AML/CFT regime in Mauritius have been disproportionately high relative to the size of its financial sector and its IFS industry. The consultants are of the view that those costs (in relative and absolute terms) have hurt the MC industry and made it less competitive and profitable.

- The total benefits - allowing for an element of double-counting - derived from the IFS industry (in terms of value addition, export earnings, employment and profitability) were estimated to be just over US\$450 million over the period 2002-05. Those benefits have to be judged against total regulatory costs, rather than just the incremental regulatory costs for AML/CFT. With incremental costs being estimated at US $\$ 40$ million and assuming, reasonably generously, that the incremental costs were about 25 per cent of total regulatory costs (the FSC's incremental AML/CFT cost calculations work out to being less than 7.5 per cent of its total regulatory cost, while for the BoM they work out at 2.6 per cent of its total regulatory cost) that would yield a figure of total regulatory costs of US $\$ 160$ million, yielding an overall cost-benefit ratio of 1:3 - i.e. a very low proportion.

- If the FSC's ratio was used, total regulatory costs would amount to over US\$530 million, which is an obviously ludicrous estimate. The BoM's ratio would yield a total regulatory cost of US\$1.6 billion, which is even worse! Using these ratios, there would be negative net benefits from the operations of the IFS sector. This illustration, resulting from applying imputed ratios, underlines the point that the FSC's and the BoM's calculations of their own incremental costs of AML/CFT are probably too low. Their incremental costs for applying the new AML/CFT regime since 2002 have probably been in the range of $15-25$ per cent of their total regulatory and supervision costs. Using those more realistic ratios, the total cost to the public sector would increase from US $\$ 4.8$ million to over US\$7 million.

- The argument of regulators in Mauritius is that adopting the new AML/CFT regime has enabled the IFS industry to survive. Had the new regime not been implemented, Mauritius would have been blacklisted. The damage to its reputation would have meant a certain loss of business. Thus the net benefits associated with implementing the new regime are equivalent to the benefits presently being generated by the IFS industry. That would effectively mean counting the entire benefit of US $\$ 450$ million from IFS operations calculated earlier as an incremental benefit for the purposes of deriving the incremental cost-benefit ratio. Using the estimate of US $\$ 40$ million as the cost incurred, the incremental cost-benefit ratio would be around 1:11. However, this argument needs to be looked at more closely.

- First, is it certain that Mauritius would have been blacklisted on the basis of its previous record and performance? Russia, Indonesia, Israel and China have not been blacklisted, although their regulatory environments are much less stringent than that of Mauritius. Their stance vis-à-vis the FATF can hardly be characterised as being 'co-operative'. Or was the threat of blacklisting a convenient argument for 
domestic regulators and policy-makers to use in persuading the industry that they had no choice but to do what they did? Admittedly the regulatory juggernaut launched by the FTAF (or the regulatory tsunami as it has colloquially been referred to in The Economist) and which has been rolling unstoppably downhill since 2001, did run the risk of Mauritius being run over and injured had it stood in the way of the FATF and its implementing agencies, the IFIs. However, unlike many other OFCs, Mauritius had a reasonably good regulation prior to 2001. Did its policy-makers do enough to explain that environment to the IFIs and the FATF and make the case that only marginal adjustments were necessary to bring it into line with new standards? Or did they accept every recommendation of the FSAP mission, because that was the path of least resistance? Did policy-makers make the 'risk-based' case that, when it came to AML and CFT, Mauritius simply did not confront the same risks as say Colombia, Pakistan, a Middle-Eastern OFC, or Jamaica in the Caribbean or even, for that matter, the US and EU with their very large underground economies creating much greater scope for money laundering activities and attracting a far greater amount of terrorist financing; so that imposing a draconian AML/CFT regime would add cost, but yield little benefit?

- The evidence is too thin and the study could not go into the detailed history of negotiations with the OECD, IFIs and the FATF (nor was it mandated to) to reach any definitive conclusions on this politically sensitive issue. The view of the IFS industry is that Mauritian policy-makers did not fight their corner hard enough, although that may well be unfair. Nor did policy-makers consult with the industry before making commitments that damaged the industry's interests. The study does note that most offshore clients of the Mauritian IFS industry are Indian, Indonesian, Chinese or African. India had not started discussions with the FATF until late 2005; China had not done so at the time of writing. The other clientele come from countries that have problems meeting FATF demands. So, it would have been odd if these clients suddenly abandoned Mauritius because of blacklisting by FATF, assuming that had occurred.

- Second, the argument that, since new AML/CFT regulatory requirements enabled Mauritius to continue operating its IFS industry, all the ensuing benefits must be seen as incremental holds no water. It discounts the fact that almost the same magnitude of benefits were flowing before 2001. Most of them would have continued to flow regardless. The IFS industry could not have been switched off that easily, whatever the FATF decided to do within the bounds of legality. For these and other reasons, the study aligns itself with the IFS industry in concluding that incremental benefits flowing from the tighter AML/CFT regime are difficult enough to identify, leave alone quantify. It goes a step further in believing, on the basis of evidence available, that there were almost no incremental benefits accruing from the tightened regulatory regime.

- The inability of an enhanced reputation to translate into tangible business benefits raises three critical questions. First, do the clients of Mauritius' IFS industry see it 
as having an enhanced reputation as a result of tightened AML/CFT regulation? Or is that merely an axiomatic assumption being made by regulators (and, to an extent, by the IFS industry) that is unsupported by evidence? Do offshore clients see Mauritius as having its reputation enhanced, or do they see its new regulatory regime as having become insufferably inflexible, rigidly bureaucratic, too demanding of information requirements that are of questionable value, and too intractable to deal with? Second, assuming reputation has been enhanced, why is Mauritius finding it so difficult to attract new business from potential clients and more business from existing clients? Third, is it the complacency and lack of aggressiveness of the IFS industry (three or four large firms being the exceptions) that has prevented the intangible benefit of reputation being translated into the more tangible benefit of increased business and revenues?

- The study concludes that the answer to the first question is in the affirmative: i.e. although it is assumed by its regulators that Mauritius' reputation has definitely been enhanced, that enhancement may be in their own eyes and those of the country's official international interlocutors only; it is also a view shared by some players in the IFS industry. However, the fact that reputation has not been translated into business may suggest that it is not a view shared widely by MCs or by clients of its offshore financial industry. It is their views that matter if business is to be derived.

- The second question is more difficult to answer definitively. However, several indicative strands are visible. To begin with, there are now many more OFCs/IFCs for clients from source countries important to Mauritius to choose from. These OFCs/IFCs are generally easier to do business in and include Bahrain, Dubai, Muscat, Doha, Labuan (Malaysia), Singapore, Hong Kong, Switzerland and London. Moreover, Mauritius has not yet opened up entry to its IFS industry to offshore players, whom their own clients may be more comfortable dealing with. Mauritius may also be too remote geographically and 'off the beaten path'. However, these are more speculations rather than explanations backed by evidence.

- The third question also has an indicative answer in the findings of the survey. When asked whether players in the IFS industry had undertaken or witnessed either geographical diversification of their client base or functional diversification of the products/services they offered, the responses were tilted toward the negative. Also, the findings of the study indicate that the IFS industry derived few sidebenefits from its improved technological capacity, expanded knowledge base, and improved risk-management capacity that resulted from complying with enhanced regulatory demands. That makes the IFS industry, which is quick to blame regulatory burdens for its travails, vulnerable to the counter-accusation levelled by some regulators that the industry is itself too complacent, conservative (perhaps too protected in its domestic business space) and diffident to make the strategic and tactical effort that is necessary in a much more competitive world; i.e. to really go out and compete with more aggressive players from elsewhere. 
- Where incremental benefits and costs of AML/CFT regulation and compliance are concerned, most governments/regulators confront a trade-off between: (a) the reputational benefit of adhering to international standards of regulation/compliance for AML/CFT; and (b) the public + private financial costs that are borne by the IFS industry, along with wider social costs incurred as a result of regulationinduced inefficiencies, which are borne by domestic and external consumers of IFS. Has Mauritius made the correct trade-off? In the view of the authors of this study, it has not. Being overly anxious to please its external interlocutors, Mauritian policy-makers and regulators have traded-off the interests of the IFS industry, its offshore clientele and its own national interest. That trade-off has favoured costs over benefits. As a consequence, the actions of policy-makers have imposed too high a cost burden on the IFS industry in making commitments they perhaps did not fully appreciate the consequences of. That they did so without any prior consultation with the IFS industry beggars belief.

- Two other questions, concerning the actions of policy-makers and regulators, arise in introducing and implementing the FATF/IFI recommended AML/CFT regime. The first is whether regulators were over-zealous in applying the new international standards to the detriment of the IFS industry and its clientele? The second is whether introduction of the new AML/CFT regime provided an opportunity for indulgence in classic bureaucratic behaviour concerning the capturing of larger budgets, building of empires, protection of turf, and the exercise of personal vested interests (i.e. career, travel, etc.). The study did not look into these issues specifically. However, its findings do touch upon prima facie evidence of whether this happened.

- Again, the answer to the first question is 'perhaps'. The study did not go into examining in minute detail all the supporting information that is now required by regulators from MCs and banks to satisfy KYC and DD requirements, although the consultants are fully aware of what such requirements are. However, the anecdotal evidence, and the IFS industry's reactions, both suggest that Mauritian regulators may have gone overboard in requiring unduly extensive (and perhaps even irrelevant) documentation for KYC purposes. They may also have gone overboard in reviewing and interpreting such evidence in ways quite different from other jurisdictions. However, the study cannot be definitive about this. It can only raise the issue as a concern that needs further exploration. What the study can be definitive about (from the seminar discussions) is that regulators have unnecessarily added to $\mathrm{MC}$ and client costs by not co-ordinating better among themselves and requiring the same information on KYC/DD to be replicated at least twice in MCs and banks (and occasionally four times when insurance companies and securities brokerages get involved) simply because they are regulated by different institutions, which do not accept one another's findings on verification.

- As for the empire-building argument that has been levelled by many in the IFS industry, the prima facie evidence creates a degree of discomfort that this may well have happened. It has not happened at the BoM where, despite a considerable 
additional regulatory/supervisory burden, there has been almost no increase in total staffing and no extraordinary increase in the operating budget of the Bank. There has been only a small reallocation of staff to regulation and supervision functions from other functions. In private conversations, senior management of the BoM indicated that the Bank had perhaps overstretched its existing staff resources to meet incremental regulatory burdens and that this approach had now reached its limits. On the other hand, the staff and budget of the FSC has doubled since its inception, while the FIU seems distinctly over-staffed and over-resourced. However, these impressions and indicators are superficial. They need to be confirmed through more detailed analysis. With a new CEO, the FSC appears to be entering a phase of consolidation with a changed approach to regulation. It does have a large mandate and considerable ground to cover, so that a large part of the increase in staffing and budget may well be justified. However, that is not quite as obviously apparent in the case of the FIU.

- Finally, the findings of the study indirectly call into question the way in which external pressures are applied by organisations like the OECD, FSF and the FATF, through the agency of IFIs, on small jurisdictions offering international financial services. They raise uncomfortable issues about the quality of analysis undertaken by these institutions in the first place. For example, there was no justification for the FSF's listing Mauritius as a Category III jurisdiction in assessing the quality of its supervision regime. Such organisations also exercise arbitrary and asymmetrical power in international relations. There is a fundamental inequity in the behavioural duality of international institutions bullying those they can (like small island states with insufficient countervailing power) while side-stepping or treating very carefully those they can't (like Russia, China and India). That duality raises equally fundamental concerns about 'level playing fields'. It also raises questions about: the proportionality of the response to AML and CFT concerns (especially after the events of 9 September 2001); what the FATF and IFIs recommend in the context of particular jurisdictions; and whether their 'one-size-fits-all' approach in matters of financial system regulation and the setting up of financial intelligence units from the same mould in all cases is at all appropriate or sound.

- The findings of the study should give the FATF and IFIs pause to reconsider what they have been doing over the last four years and reach more temperate judgements about whether their ministrations might be unfair and inimical to the legitimate interests of small financial jurisdictions providing IFS and whether they are contributing to strengthening or weakening global financial regulation.

These conclusions represent, reasonably exhaustively, the findings of the study in Mauritius. While it is tempting to leap from arriving at defensible (if contentious) conclusions to making specific recommendations for policy-makers, regulators and the IFS industry, the study desists from doing so for a number of reasons. First, it has no mandate to do so. Second, the analysis undertaken was more from the research viewpoint rather than for prescriptive purposes. Third, in order to make recommendations 
the study would need to confirm its prima facie impressions with more detailed analysis undertaken in a consulting frame of mind.

For the astute regulator, policy-maker and MC/bank manager, the study is replete with a number of findings and observations that lead to some rather obvious conclusions about what might be done to remedy situations that are clearly not satisfactory. However, those are left for readers to draw out and act upon. Should the Government of Mauritius seek, through the good offices of the Commonwealth Secretariat, to have specific recommendations made by the lead consultants based on the findings of the study, that request could readily be acted upon with a modicum of further work being done to confirm the judgements arrived at.

Finally, the findings of the study for Mauritius certainly reinforce the quote ascribed to Graham Dillon of KPMG by The Economist in its Special Report on Financing Terrorism (October 22 2005) when speaking about the impact on the global economy of the additional costs imposed by the FATF requirements on countering financing of terrorism (the quote applies with equal force to anti-money laundering measures as well):

'The cost (of these measures) to our global economy is so large they've (i.e. terrorists) already had the effect they wanted. The increasing costs of compliance and technology are a form of terrorism. We're damaging ourselves'.

\section{Notes}

1. OECD (1998).

2. Financial Services Commission (2003, 2004, 2005).

3. This followed discussions with incoming FSC staff who were less biased than former staff (who were anxious to downplay the cost impact on the FSC of new AML-CFT regulations, which they had adopted and applied unquestioningly and perhaps even unthinkingly). Each line item was re-assessed and FSC staff gave opinions of what proportion of each line item might be apportioned to AML-CFT.

4. Following discussions at the seminar it became clear that the scale had not suggested to respondents that a rating of ' 3 ' reflected 'no opinion'. Many respondents thought they were providing a safe middle-of-the-road answer by ticking ' 3 ' without quite realising what that score conveyed. 